\author{
ОСОБЕННОСТИ ФОРМИРОВАНИЯ СТРУКТУРЫ \\ КАРБИДА НИОБИЯ В ЛИТЫХ ЖАРОПРОЧНЫХ СПЛАВАХ \\ HА ОСНОВЕ СИСТЕМЫ Fe-Cr-Ni
}

\author{
S.Yu. Kondratyev, E.V. Sviatysheva, G.P. Anastasiadi, M.A. Danilova
}

\title{
FEATURES OF NIOBIUM CARBIDE STRUCTURE FORMATION IN CAST HEAT RESISTANT ALLOYS OF THE Fe-Cr-Ni SYSTEM
}

\begin{abstract}
Методами оптической и электронной микроскопии изучено строение упрочняющих частиц карбида ниобия в литом жаропрочном сплаве на основе системы Fe-Cr-Ni-C, модифицированном $\mathrm{Nb}$ и Тi. Частицы карбида ниобия в структуре литого сплава преимущественно являются многофазными поликристаллическими кластерами, неоднородными по химическому составу и кристаллическому строению. Угол разориентировки между отдельными кристаллами, образующими карбидную частицу, составляет $30-60^{\circ}$. Поликристаллический характер карбидов, вероятно, связан со значительными термическими напряжениями, возникающими на межфазных границах в структуре сплава при первичном охлаждении слитка. Для объяснения полиморфизма кластера карбида ниобия требуется дальнейший анализ на основе структурной и геометрической кристаллографии.
\end{abstract}

ЛИТЫЕ ЖАРОПРОЧНЫЕ ЖАРОСТОЙКИЕ СПЛАВЫ; МИКРОСТРУКТУРА; ФАЗОВЫЙ СОСТАВ; ЭЛЕКТРОННАЯ МИКРОСКОПИЯ; КАРБИДНЫЕ ФАЗЫ; ФАЗОВЫЕ ПРЕВРАЩЕНИЯ.

\begin{abstract}
The structure of reinforcing particles of niobium carbide in a cast superalloy based on the $\mathrm{Fe}-\mathrm{Cr}-\mathrm{Ni}-\mathrm{C}$ system, modified with $\mathrm{Nb}$ and $\mathrm{Ti}$, was studied by optical and electron microscopy. Niobium carbide particles in the cast alloy structure are mainly multiphase polycrystalline clusters with heterogeneous chemical composition and crystal structure. The disorientation angle between the individual crystals forming carbide particles is $30-60^{\circ}$. The polycrystalline nature of carbides is probably associated with significant thermal stresses occurring at the interfaces in the alloy structure during the initial cooling of the ingot. For an explanation of the polymorphism of niobium carbide clusters, further analysis on the basis of structural and geometric crystallography is required.
\end{abstract}

CAST HEAT-RESISTANT HEAT RESISTING ALLOYS; MICROSTRUCTURE; PHASE COMPOSITION; ELECTRON MICROSCOPY; CARBIDE PHASES; PHASETRANSFORMATIONS.

\section{Введение}

Литейные жаропрочные сплавы $\mathrm{Fe}-25 \mathrm{Cr}$ $35 \mathrm{Ni}-\mathrm{C}$ с добавками ниобия и титана широко используются в качестве конструкционных материалов в нефтехимической промышленности и печах риформинга [1-4]. Детали из них изготавливают литьем в песчаные формы (арматура, фитинги) или центробежным (трубы). Струк- тура сплавов в литом состоянии состоит из различных фаз и структурных составляющих: 1) матричного $\gamma$-твердого раствора на основе $\mathrm{Fe}-\mathrm{Cr}-\mathrm{Ni} ; 2)$ эвтектики ( $\gamma+$ карбиды на основе хрома или ниобия), выделяющаяся при кристаллизации сплава; 3) матричных или зернограничных отдельных включений карбидов хрома и ниобия [5-7]. Суммарное содержание карбидов хрома в структуре литых сплавов составляет 
$\sim 3$ об. \% и карбидов ниобия - 1,5 об. \%. Такая структура обеспечивает хороший комплекс свойств сплавов для экстремальных условий эксплуатации: при температурах $900-1150{ }^{\circ} \mathrm{C}$ и рабочих напряжениях 5-10 МПа. Однако работоспособность сплавов определяется не только уровнем свойств, но и структурной стабильностью в течение длительного времени.

В недавних публикациях [8-17] показано, что при высокотемпературной эксплуатации структура сплавов, в том числе ее карбидная составляющая, претерпевает непрерывную трансформацию. Принято считать, что карбиды хрома менее стабильны, чем карбиды ниобия, и в последние годы опубликовано много работ, посвященных изучению их структуры и превращений [1, 5-8, 12-13, 18-19]. Однако карбиды ниобия также подвергаются изменениям при температурах эксплуатации жаропрочных $\mathrm{Fe}$ Cr-Ni сплавов [15-18, 20-22]. Кратковременная высокотемпературная выдержка незначительно увеличивает, а более длительная - уменьшает количество карбидов ниобия в структуре сплавов. При этом их морфология существенно изменяется: относительная доля мелких карбидов ниобия (средний диаметр менее 2 мкм и площадь 1-20 мкм²) в общем количестве этой фазы в структуре литых сплавов возрастает примерно в 2 раза, а включений других размеров - уменьшается [23]. Известно также, что при температурах 700-1000 ${ }^{\circ} \mathrm{C}$ первичные карбиды ниобия частично превращаются в никель-ниобиевые силициды, обозначаемые как $G$-фаза [24, 25]. Необходимо также отметить, что карбиды ниобия могут иметь разную морфологию в зависимости от условий кристаллизации сплава [20, 21]. Следовательно, необходимо более полно изучить морфологию и строение первичных включений карбидов ниобия, чтобы оценить структурную стабильность $\mathrm{Fe}-\mathrm{Cr}-\mathrm{Ni}$ сплавов в процессе эксплуатации.

Цель работы - микроскопическое исследование строения частиц карбидов ниобия и анализ их структуры в литом сплаве $\mathrm{Fe}-25 \mathrm{Cr}-35 \mathrm{Ni}-$ $0,4 \mathrm{C}-\mathrm{Nb}-\mathrm{Ti}$.

\section{Материал и методика исследований}

Сплав для исследования выплавляли в индукционной печи. Заготовки получали статическим литьем в песчаные формы и центробежным литьем. Химический состав, масс. \%, выплавленного сплава НP 40 NbTi следующий:

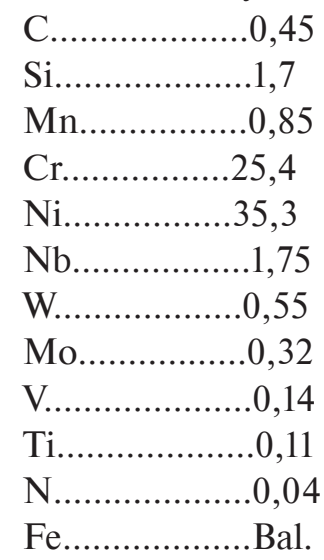

Образцы размером $10 \times 10 \times 15$, мм, вырезали на высокоскоростном отрезном станке и использовали для металлографических исследований в литом состоянии сплава.

Для выявления структуры сплава при анализе на оптическом микроскопе применяли травитель Каллинга. Тонкие фольги для анализа в электронном микроскопе приготавливали электрополированием в $10 \%$-м растворе щавелевой кислоты при 50 В и последующим утонением ионным лучом. Использовали сканирующий двухлучевой электронный и ионный микроскоп Quanta 200 3D FEG. Металлографический и микрорентгеноспектральный анализы, а также рентгеноструктурное картирование выполняли, используя оптический микроскоп Carl Zeiss Axiovert 40 просвечивающий электронный микроскоп (ПЭМ) FEI's Tecnai G 30 S-TWIN с ускоряющим напряжением 200 кB, оснащенный энергодисперсионным спектрометром (ЭДС), и сканирующий электронный микроскоп (СЭМ) TESCAN VEGA 2 LM, оснащенный автоэмиссионной пушкой и энергодисперсионным спектрометром INCA X-MaX-50.

При выборе методики исследования необходимо учитывать, что карбидные включения в сплавах исследуемого типа дисперсны. Так, 
относительная доля частиц средним диаметром 1-10 мкм составляет $90 \%$ в общем объеме карбидов ниобия в структуре литого сплава $\mathrm{Fe}-$ 25Cr-35Ni-C-Nb-Ti, включая $30 \%$ включений менее 2 мкм [23]. Определить тип кристаллической решетки мелких карбидов по одной электронограмме невозможно. При небольшом размере частиц на электронограмму попадают рефлексы от матрицы или других фаз. По этой причине в работе использовали метод одиночных рефлексов [26]. Суть метода состоит в том, что, ограничив селекторной диафрагмой изучаемую область фольги и меняя дифракционные условия, необходимо обнаружить хотя бы один рефлекс, соответствующий анализируемой частице карбида. Электронограммы, полученные с использованием ПЭМ при разной пространственной ориентации образца в момент съемки, обрабатывали при помощи программы ImageJ. Проводили измерения величин, позволяющих идентифицировать частицы карбидов ниобия по параметрам кристаллической решетки и химическому составу (с учетом результатов элементного анализа идентифицируемой частицы), а именно: 1) расстоянию между центральным пучком и рефлексом, полученным от соответствующей частицы; 2) углу между горизонтальной линией, проведенной из нулевого рефлекса, и

a)

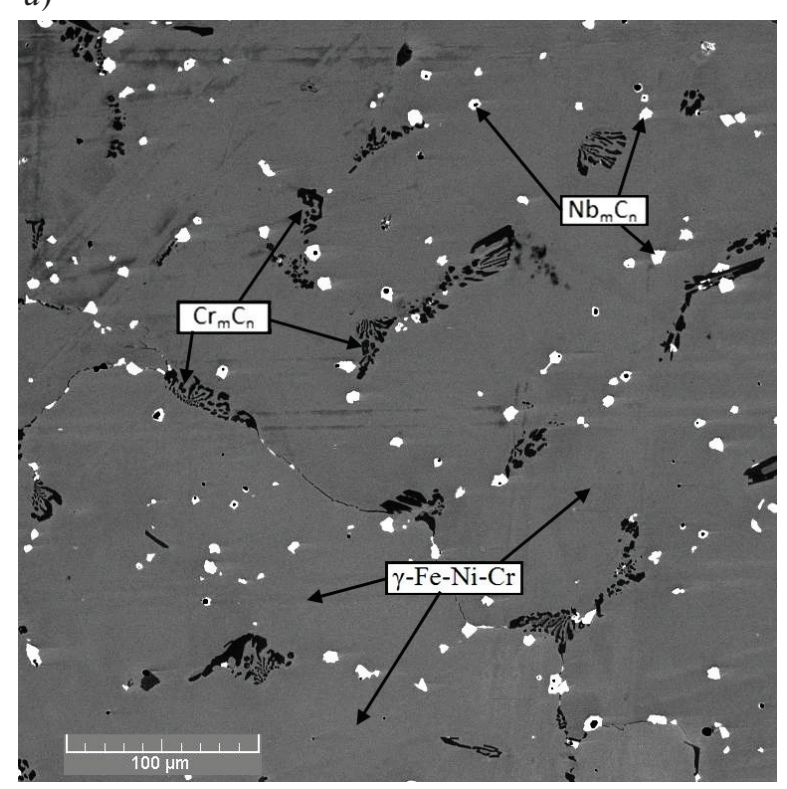

лучом, проходящим через нулевой рефлекс и рефлекс от исследуемой частицы. Также при идентификации использовали величину угла наклона образца в момент съемки, которую получали непосредственно с ПЭМ в момент съемки электронограммы. Получив несколько рефлексов с соответствующими угловыми характеристиками, описывающими пространственную ориентацию образца в момент съемки, можно вычислить набор межплоскостных углов и расстояний. Результаты заносили в таблицу, на основании которой, используя программу Reflex, идентифицировали исследуемую фазу. Для этого сравнивали полученные экспериментальные результаты со значениями межплоскостных расстояний, приведенными в компьютерном варианте PDF-2 картотеки JCPDS-ASTM. В программу вводили экспериментальные данные по рефлексам и задавали допустимую погрешность по углам. С увеличением количества рефлексов, учитываемых в идентификации, перечень фаз, соответствующих комплексу используемых рефлексов, уменьшается. В итоге остается одна фаза, соответствующая полученному набору рефлексов с максимальной вероятностью (минимальному среднеквадратичному отклонению экспериментальных значений межплоскостных углов и расстояний от табличных).

б)

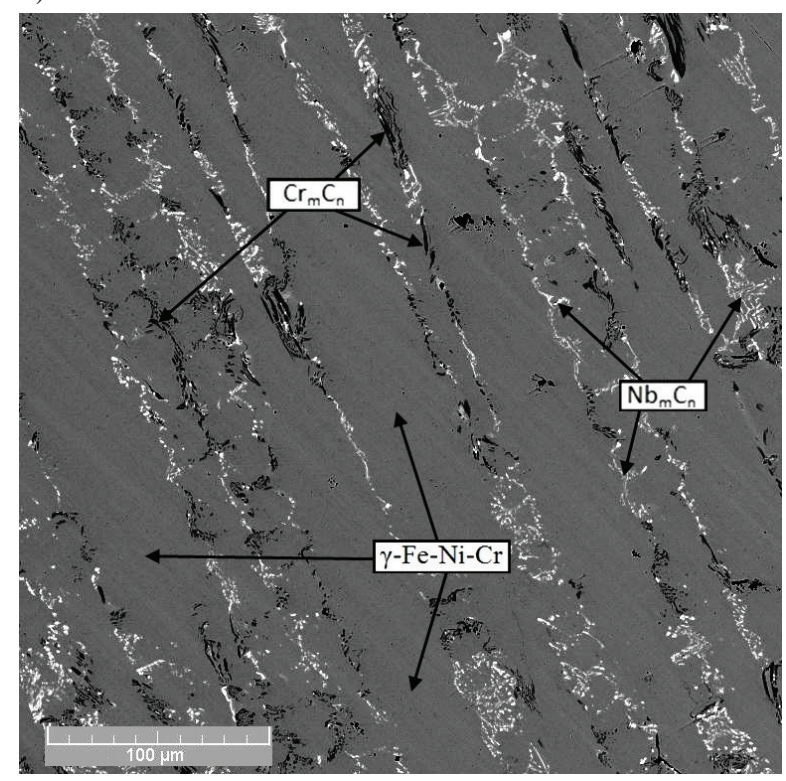

Рис. 1. Микроструктура литого сплава: $a$ - статическое литье в песчаные формы; $\sigma$ - центробежное литье. СЭМ 


\section{Результаты исследований и их обсуждение}

На рис. 1 показана микроструктура сплава после статического ( $a$ ) и центробежного (б) литья. Структура литого сплава в обоих случаях состоит из зерен $\gamma$-фазы, эвтектики $(\gamma+$ карбиды) и отдельных включений карбидных фаз в матричной $\gamma$-фазе.

Матричный твердый раствор является неоднородным и характеризуется грубой дендритной ликвацией. Длина ветвей первого порядка достигает 3000 мкм, ширина - 200 мкм; ветвей второго порядка - соответственно 300 и 100 мкм. Эвтектика расположена по границам матричных зерен. Результаты электронной микроскопии и рентгеноспектрального микроанализа показали, что состав эвтектических и матричных карбидов зависит от скорости охлаждения в процессе кристаллизации. При использовании статического литья эвтектика состоит из $\gamma$-фазы и карбидов хрома, матричными карбидами являются карбиды ниобия (рис. $1, a)$. При использовании центробежного литья эвтектика содержит $\boldsymbol{\gamma}$-фазу, карбиды хрома и карбиды ниобия; матричными карбидами являются дисперсные карбиды хрома, выявляемые при большом увеличении микроскопа (рис. 1,б). Это различие в составе эвтектики в структуре сплава связано с более высокой скоростью охлаждения в процессе кристаллизации при использовании центробежного литья (в 5-10 раз больше) по сравнению со статическим песчаным литьем.

Объемное содержание включений карбида ниобия в структуре литого сплава составляет $1,5 \%$, а их размер в сечении изменяется от долей микрона до 10 мкм, причем доля мелких (менее 2 мкм) карбидов составляет $\sim 30 \%$ в их общем количестве.

При большом увеличении электронного микроскопа выявлено, что большинство включений карбида ниобия, особенно более крупных, представляет собой кластер, состоящий из нескольких кристаллитов неправильной формы (рис. 2, 3,a). Средний размер в сечении отдельных кристаллитов находится в пределах 0,3-1,5 мкм (в зависимости от размера кластера). На рис. 2 представлены карты ориентировок кристаллов, образующих кластер $\mathrm{Nb}_{m} \mathrm{C}_{n}$. Локальная ориентировка относительно макроскопических осей ко- ординат RD (reference direction) и TD (transverse direction) закодирована цветом в соответствии с раскраской инверсного треугольника. Замкнутые области с одинаковой ориентировкой (раскраской) могут рассматриваться как кристаллиты с единой ориентировкой. Карта ориентировок подтверждает поликристаллический характер карбидов ниобия. В центре такого кластера может находиться карбонитрид титана $\operatorname{Ti}(\mathrm{CN})$, вокруг которого располагаются кристаллы карбида ниобия (рис. 3,a, 4). Образование мелкодисперсных частиц, содержащих кристаллы различного химического состава, - распространенное явление в многокомпонентных высоколегированных сплавах. Это явление обусловлено различными факторами, связанными с химической природой сплава и кинетикой роста фаз при кристаллизации из расплава: 1) неоднородностью структуры расплава при температурах вблизи температуры ликвидус, определяемой вероятностью образования в расплаве тугоплавких химических соединений; 2) различной кинетикой роста и растворения фаз; 3) влиянием внешнего теплоотвода с возникновением переохлаждения расплава и последующей рекалесценции за счет теплоты фазового преврашения - образования твердых растворов и химических соединений; 4) вероятностным термодинамическим состоянием фаз в многофазных системах, определяемым соотношением их термодинамических функций.

Образование единого комплексного неметаллического включения, состояшего из нескольких

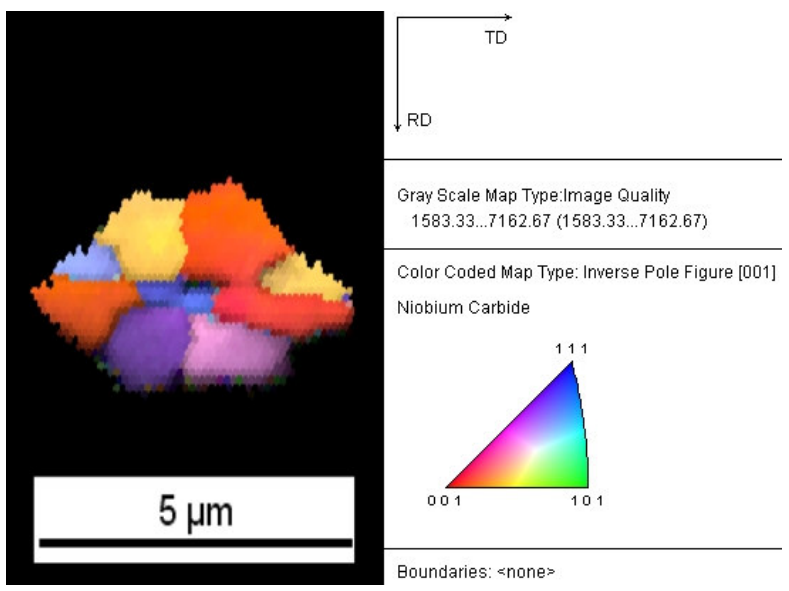

Рис. 2. Карта ориентировок кристаллов кластера карбида ниобия в структуре литого сплава. СЭM (EBSD) 


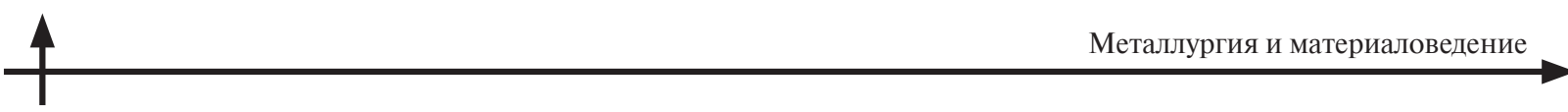

кристаллов алюминиевомагниевой шпинели $\mathrm{MgAl}_{2} \mathrm{O}_{4}$ и сульфида марганца $\mathrm{MnS}$, наблюдали в высокопрочных низколегированных сталях [27]. Многофазные дисперсные упрочняющие частицы обнаружены также в алюминиевых сплавах с добавками $\mathrm{Sc}, \mathrm{Zr}$, Li после двухступенчатого старения [28, 29]. В алюминиевых сплавах такие многофазные включения более стабильны по сравнению с самостоятельными фазами, сохраняя упрочняющий эффект при более длительном старении и при более высокой температуре. Сложная «композитная» морфология включений (NbTi)C с «ядром» карбонитрида титана в центре обнаружена в литом жаропрочном никелевом сплаве IN718 [30]. Подобные сложные частицы карбидов типа МС с включениями оксидов внутри наблюдали в жаропрочных $\mathrm{Fe}-\mathrm{Cr}-\mathrm{Ni}$ сплавах, модифицированных $\mathrm{Nb}-$ $\mathrm{Ti}-\mathrm{Zr}$ и Nb-Ti-Yb [31]. Однако в сплавах Fe-Cr-Ni «композитные» упрочняющие частицы до настоящего времени не исследовали и не идентифицировали, за исключением детальной работы Buchanan K.G., Kral M.V., Bishop C.M. [21]. Авторы [21] показали, что упрочняющая частица карбида ниобия в сплаве НP40NbTi состоит из нескольких кристаллов и содержит внутри частицу фазы на основе титана.

В нашем исследовании подробно изучено строение карбида ниобия в литом сплаве $\mathrm{Fe}$ $25 \mathrm{Cr}-35 \mathrm{Ni}-\mathrm{C}-\mathrm{Nb}-\mathrm{Ti}$. Полученные экспериментальные результаты подтверждают, что частицы карбида ниобия в структуре сплава являются поликристаллическими кластерами. Однако

$a$

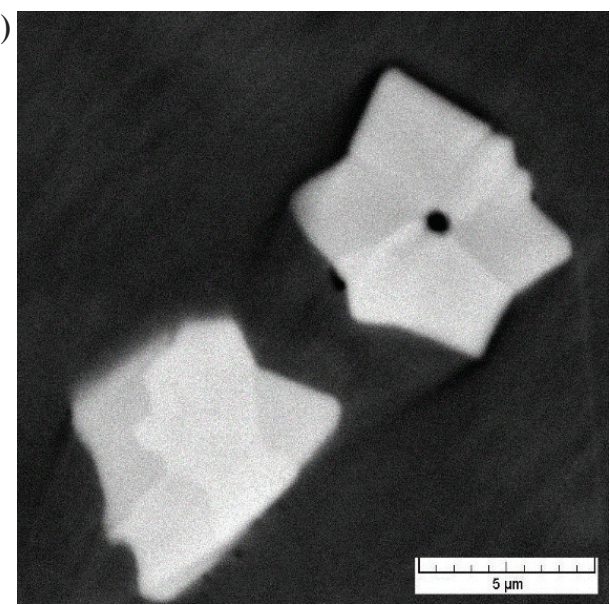

многие кластеры, состоящие из нескольких кристаллов карбида ниобия, не содержат в центре фазу на основе Тi (рис. 3). Обнаружено также, что мелкие карбиды ниобия размером в сечении меньше 2 мкм не являются кластерами. Такие включения карбидов представляют собой один кристалл (рис. 3,б).

На рис. 5 показан кластер карбида ниобия, состоящий из одиннадцати кристаллов. Для оценки типа карбида отдельных кристаллов выполнен точечный элементный анализ и построен профиль в режиме STEM (scanning transmission electron microscopy). Траектория профиля проходит через границу между двумя кристаллами кластера. На рис. 6 видно, что при переходе траектории из $\gamma$-фазы в кластер наблюдается резкое увеличение содержания ниобия, что согласуется с результатами точечного элементного анализа. При переходе из одного кристалла кластера в другой высокий уровень профиля ниобия сохраняется.

Методом одиночных рефлексов с использованием ПЭМ был определен тип кристаллической решетки отдельных кристаллов, составляющих кластер карбида ниобия. От каждого кристалла получали серию электронограмм (не менее пяти). Электронограммы обрабатывали по описанной выше методике и, пользуясь компьютерным вариантом PDF-2 картотеки JCPDS-ASTM, выбирали фазу, с наибольшей вероятностью удовлетворяющую полученным экспериментальным данным. На рис. 7-9 и в табл. 1, 2 на примере кристалла 1 (рис. 5,б) показана последовательность определения типа карбида.

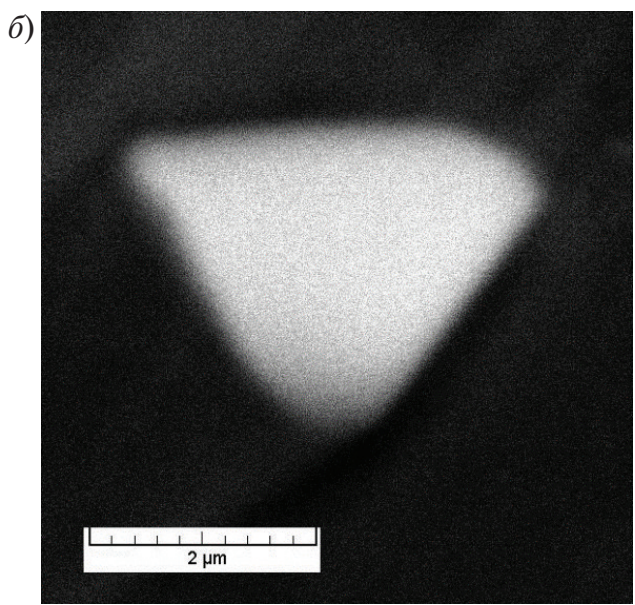

Рис. 3. Карбиды ниобия размером сечения примерно 5 мкм (a) и 2 мкм (б) в структуре литого сплава. СЭМ 
a)
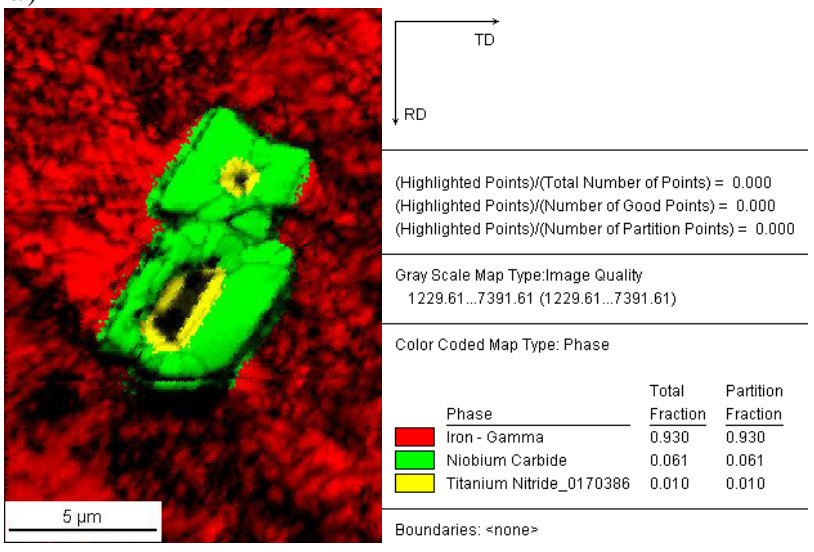

в)
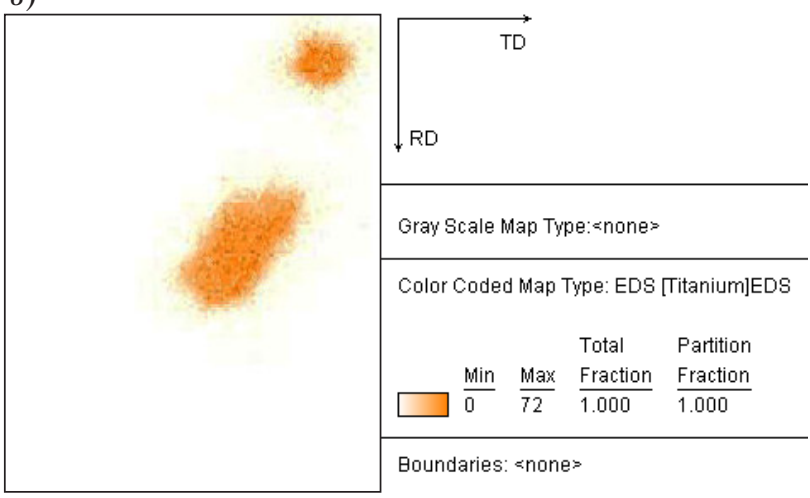

б)

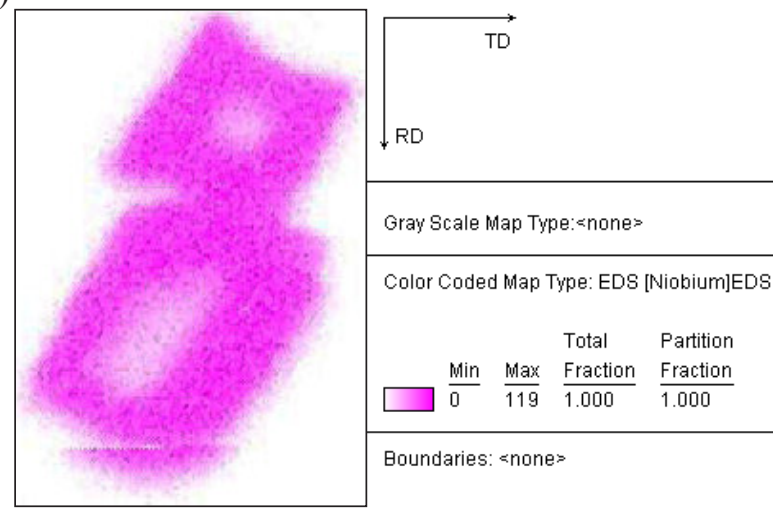

2)

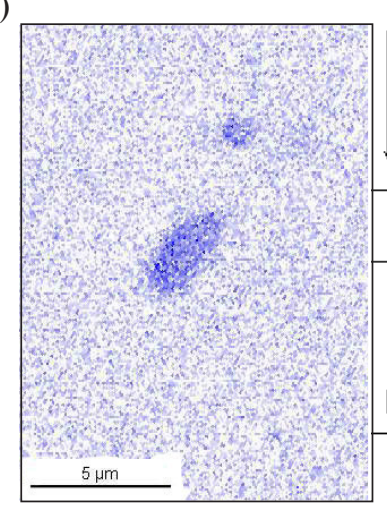

Gray Scale Map Type:«none> Color Coded Map Type: EDS [Nitrogen]EDS

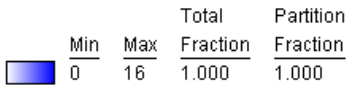
Boundaries: snone>

Рис. 4. Картирование с цветокодировкой в режиме сканирования структуры литого сплава: $a-$ по фазовому составу (NbC - зеленый, Тi(CN) - черный, $\gamma$-фаза - красный); 6 - по ниобию; $в-$ по титану; 2 - по азоту. СЭМ
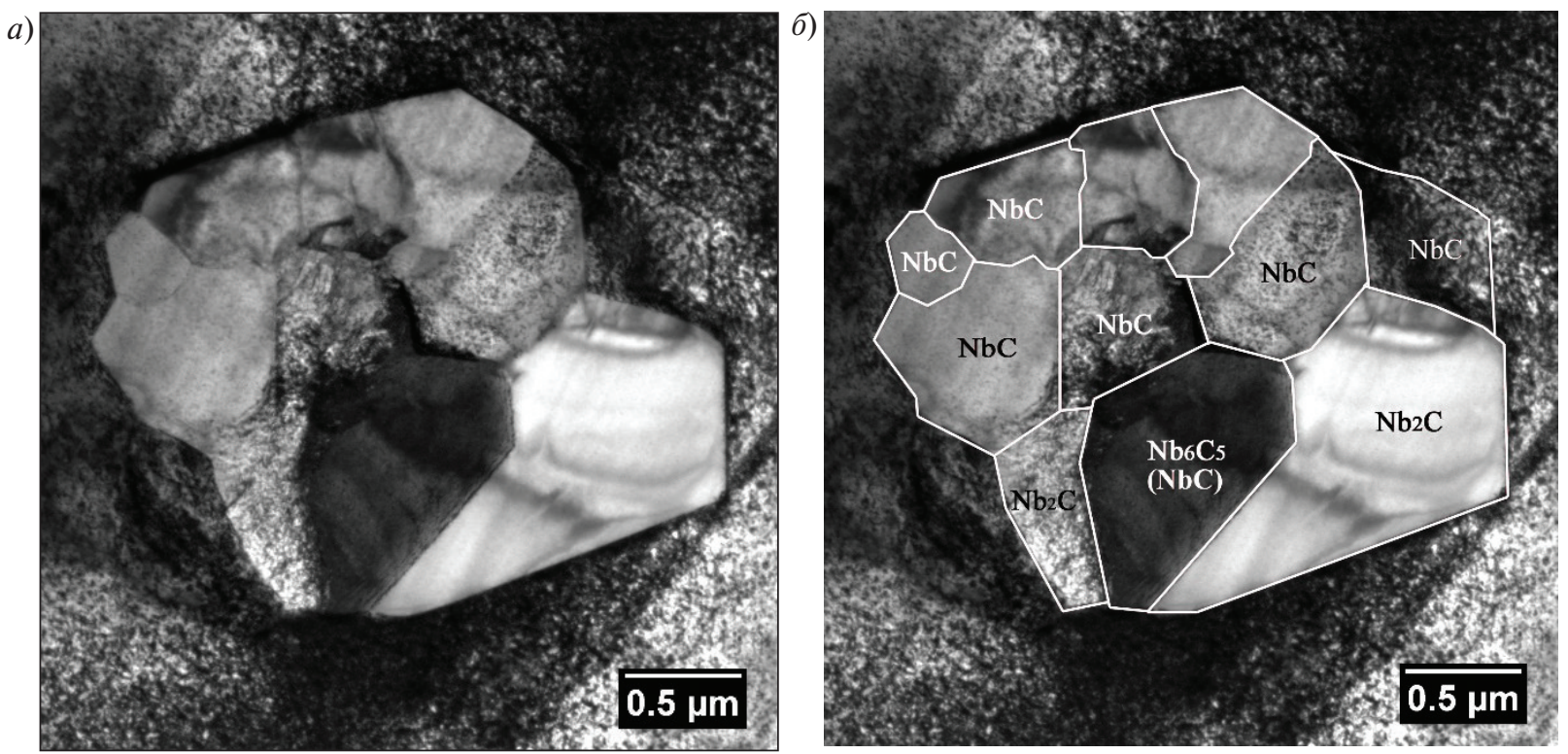

Рис. 5. Светлопольное изображение кластера карбида ниобия в структуре литого сплава: $a$ - оригинальное; б - с выделенными границами кристаллов. ПЭМ 

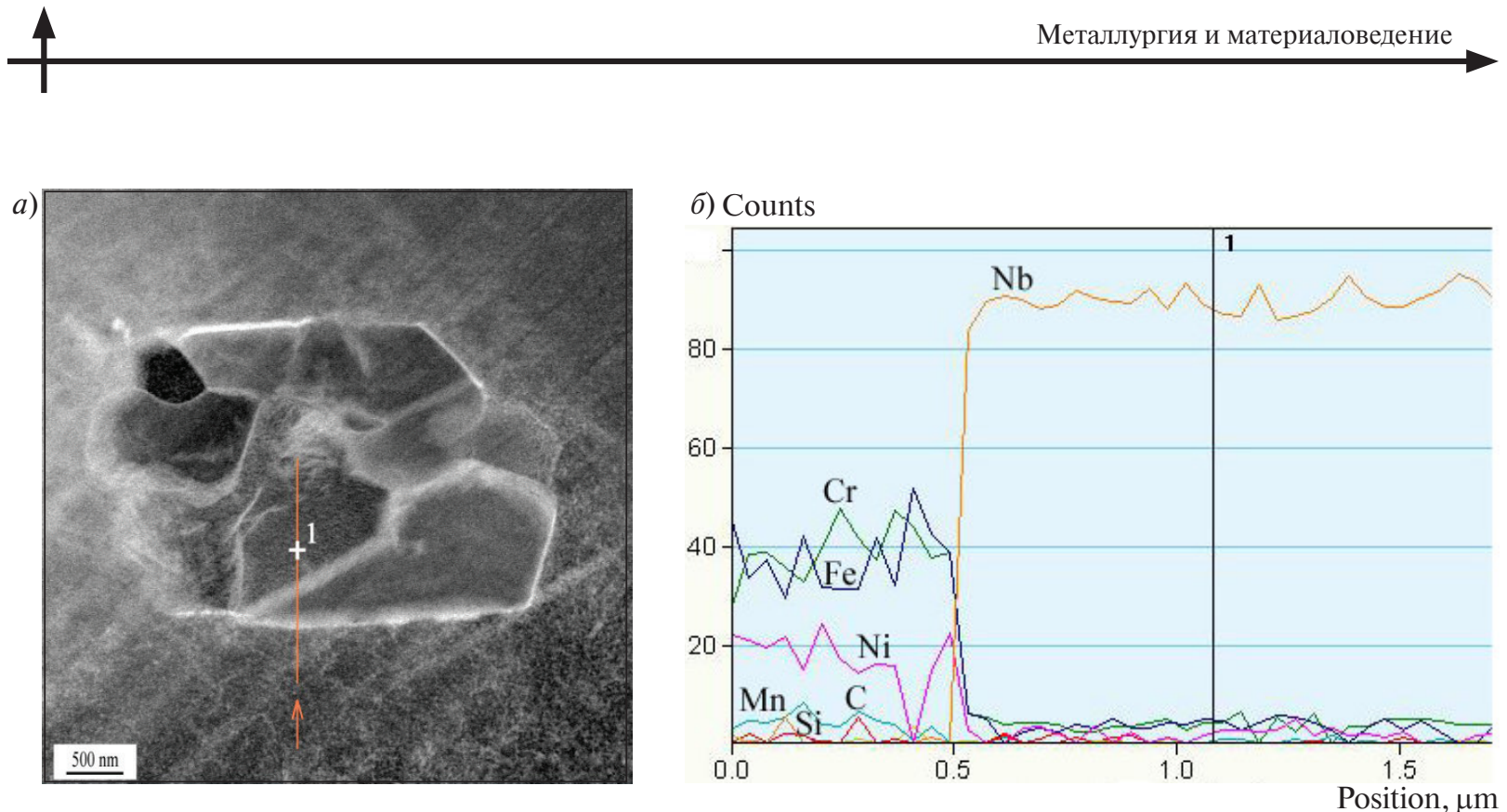

в)

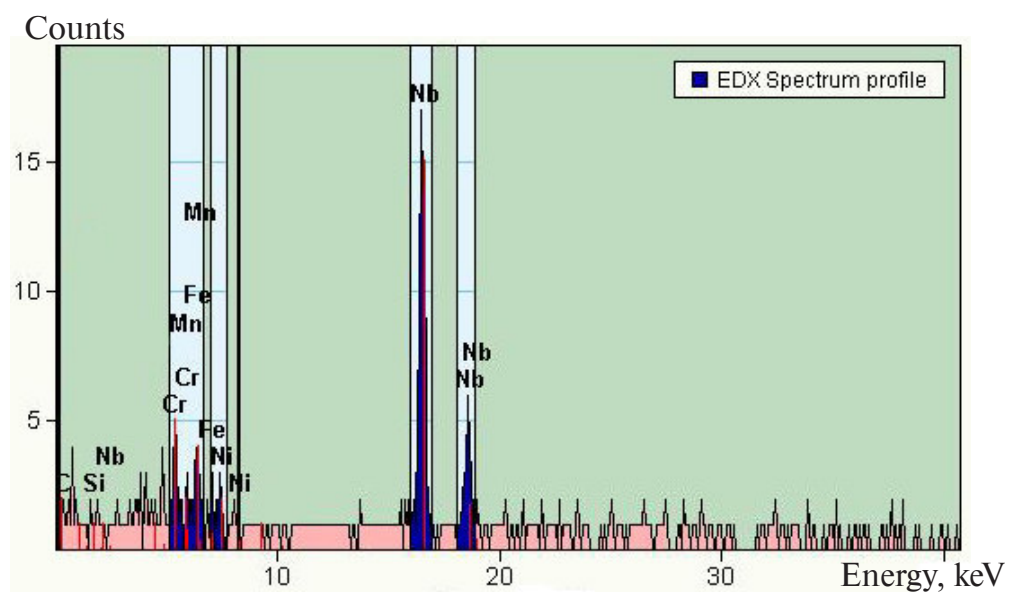

Рис. 6. Энергодисперсионный рентгеноспектральный микроанализ литого сплава: $a$ - изображение структуры с траекторией анализа; $\sigma$ - профиль распределения элементов по траектории анализа; $в$ - общий вид линий рентгеновского спектра в точке 1 . ТЕМ

a)

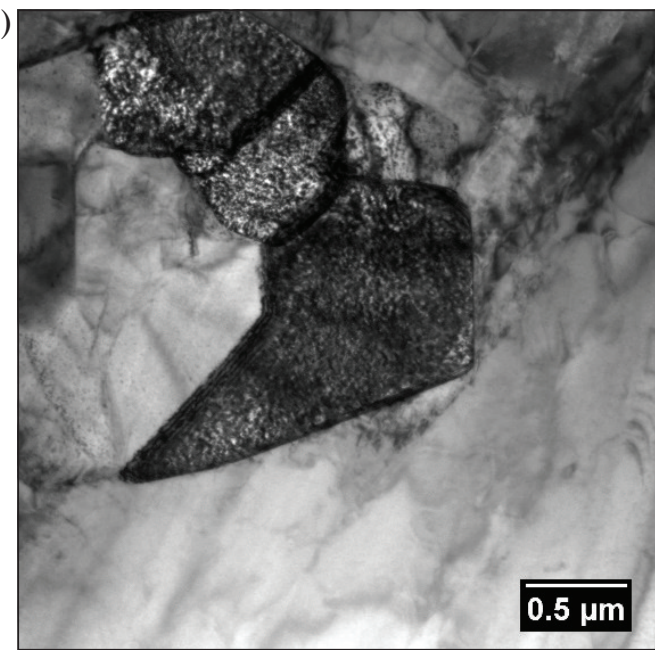

б)

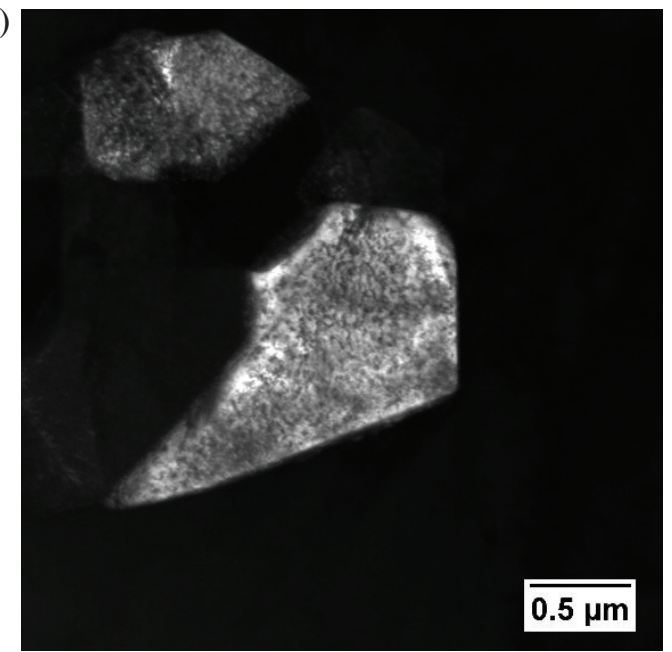

Рис. 7. Светлопольное $(a)$ и темнопольное (б) изображение кристалла 1 (по рис. 5,б) кластера карбида ниобия в литом сплаве. ПЭМ 
a)

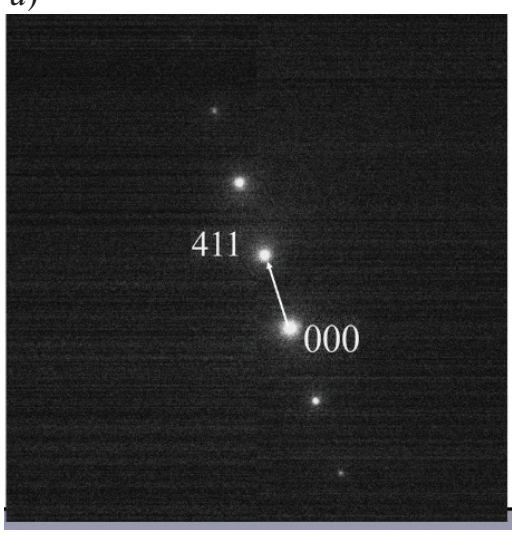

2)

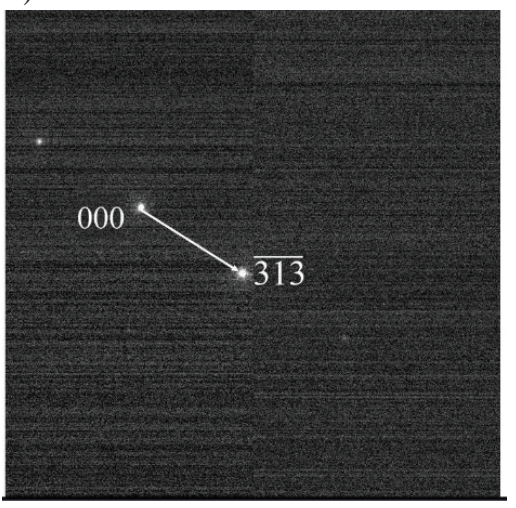

б)
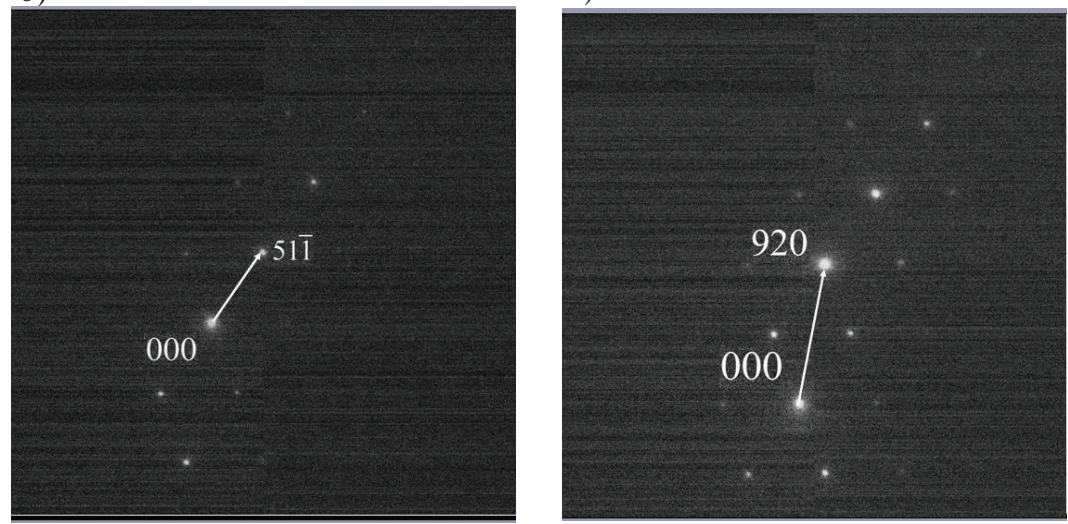

д)

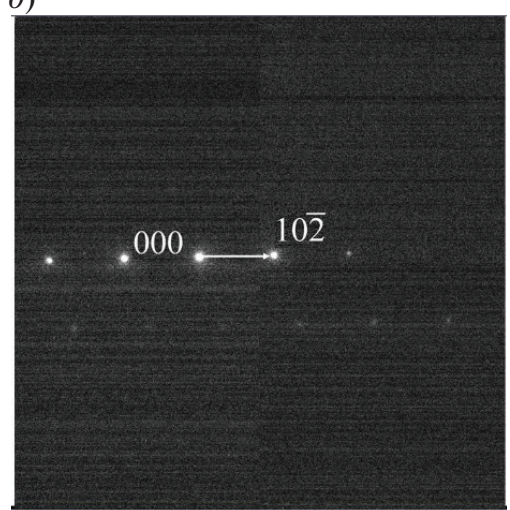

Рис. 8. Электронограммы при различных условиях дифракции $(a-\partial)$ кристалла 1 (по рис. 5,б) кластера карбида ниобия в литом сплаве. ПЭМ

Для определения типа кристаллической решетки кристалла 1 были получены рефлексы при разных положениях селекторной диафрагмы и различных углах наклона образца. Некоторые электронограммы кристалла 1 приведены на рис. 8.

По электронограммам, полученным на ПЭМ при разных углах наклона образца, для каждого рефлекса вычисляли расстояние до него от нулевого рефлекса и направление на рефлекс, а также фиксировали положение наклона образца, при котором проводилась съемка. Рассчитанные значения приведены в табл. 1. Выполненный анализ кристалла 1 (рис. 5,б) кластера карбида ниобия в структуре литого сплава $\mathrm{Fe}-25 \mathrm{Cr}-35 \mathrm{Ni}-$ $\mathrm{C}-\mathrm{Nb}$-Ті позволил идентифицировать его как карбид $\mathrm{Nb}_{2} \mathrm{C}$, который соответствует пяти рефлексам (рис. 8, $a-\partial$, табл. 1). В табл. 2 представлены параметры погрешности при идентификации кристалла по измеренным рефлексам при сравнении с табличными данными.

Таблица 1

Результаты обработки электронограмм кристалла 1 (рис. 5,б) кластера карбида ниобия в литом сплаве

\begin{tabular}{|c|c|c|c|c|c|c|c|}
\hline \multirow{2}{*}{$\begin{array}{l}\text { Рефлекс } \\
\text { на рис. } 8\end{array}$} & \multirow{2}{*}{$\begin{array}{c}\text { Наклон } \\
\text { образца, } \\
\text { град }\end{array}$} & \multicolumn{2}{|c|}{$\begin{array}{c}\text { Расстояние до } \\
\text { рефлекса, усл. ед. }\end{array}$} & \multirow{2}{*}{$\begin{array}{c}\text { Направление } \\
\text { на рефлекс, } \\
\text { град }\end{array}$} & \multirow{2}{*}{$\begin{array}{c}\text { Сопоставляемые } \\
\text { рефлексы }\end{array}$} & \multicolumn{2}{|c|}{$\begin{array}{c}\text { Угол между рефлексами, } \\
\text { град }\end{array}$} \\
\hline & & Эксперим. & Табличн. & & & Эксперим. & Табличн. \\
\hline$a$ & $+1,6$ & 2,58415 & 2,55114 & $-70,3$ & $\begin{array}{l}a, b \\
a, c \\
a, d \\
a, e\end{array}$ & $\begin{array}{c}56,12580 \\
30,06255 \\
144,01040 \\
109,11160\end{array}$ & $\begin{array}{c}56,84560 \\
30,93167 \\
144,05530 \\
109,92830\end{array}$ \\
\hline
\end{tabular}




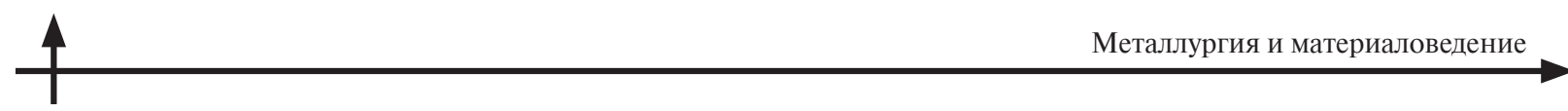

Окончание таблицы 1

\begin{tabular}{|c|c|c|c|c|c|c|c|}
\hline \multirow{2}{*}{$\begin{array}{l}\text { Рефлекс } \\
\text { на рис. } 8\end{array}$} & \multirow{2}{*}{$\begin{array}{c}\text { Н а кл о н } \\
\text { образца, } \\
\text { град }\end{array}$} & \multicolumn{2}{|c|}{$\begin{array}{c}\text { Расстояние до } \\
\text { рефлекса, усл. ед. }\end{array}$} & \multirow{2}{*}{$\begin{array}{c}\text { Направление } \\
\text { на рефлекс, } \\
\text { град }\end{array}$} & \multirow{2}{*}{$\begin{array}{c}\text { Сопоставляемые } \\
\text { рефлексы }\end{array}$} & \multicolumn{2}{|c|}{ Угол между рефлексами, град } \\
\hline & & Эксперим & Табличн. & & & Эксперим. & Табличн. \\
\hline$\sigma$ & $-7,8$ & 2,19309 & 2,16899 & $-126,1$ & $\begin{array}{l}b, c \\
b, d \\
b, e\end{array}$ & $\begin{array}{c}26,10649 \\
87,88465 \\
52,98993 \\
\end{array}$ & $\begin{array}{l}25,91393 \\
87,20966 \\
53,08270 \\
\end{array}$ \\
\hline 8 & $-7,4$ & 1,36293 & 1,33163 & $-100,0$ & $\begin{array}{l}c, d \\
c, e\end{array}$ & $\begin{array}{l}113,96340 \\
79,05969 \\
\end{array}$ & $\begin{array}{l}113,12360 \\
78,99663\end{array}$ \\
\hline 2 & $-21,9$ & 1,56179 & 1,56179 & 146,5 & $d, e$ & 34,90374 & 34,12696 \\
\hline$\partial$ & $-12,6$ & 2,53071 & 2,43625 & $-178,9$ & - & - & - \\
\hline
\end{tabular}

Таблица 2

Значения погрешности при идентификации кристалла 1 (по рис. 5,б) кластера карбида ниобия в литом сплаве по вычисленным параметрам рефлексов

\begin{tabular}{|c|c|c|c|c|}
\hline Рефлексы на рис. 8 & Тип кристалла & $\mathrm{hkl}$ & $\begin{array}{c}\text { Среднее кв. отклонение } \\
\text { по расстоянию, \% }\end{array}$ & $\begin{array}{c}\text { Среднее кв. отклонение по } \\
\text { углам, град }\end{array}$ \\
\hline$a$ & Nb2С & 411 & 5,13 & \\
(орторомб.) & $51 \overline{1}$ & & \\
$d$ & & 920 & & \\
$e$ & & $\overline{313}$ & & \\
\hline
\end{tabular}

В результате последовательного анализа методом одиночных рефлексов восьми кристаллов, образующих кластер карбида ниобия (см. рис. 5), установлено, что составляющие кластер отдельные карбиды ниобия различны по химическому составу и кристаллическому строению. Идентификация кристаллов выявила три типа карбидов - $\mathrm{NbC}, \mathrm{Nb}_{2} \mathrm{C}, \mathrm{Nb}_{6} \mathrm{C}_{5}$ [32-36], имеющих в варианте PDF-2 картотеки JCPDS-ASTM соответственно кубическую, орторомбическую, моноклинную кристаллическую решетки (рис. 9). Границы между отдельными кристаллами частицы карбида являются высокоугловыми; угол разориентировки между кристаллами составляет 30-60 ․ а между кристаллами карбида и матричной $\gamma$-фазой - примерно $60^{\circ}$.

Таким образом, микронеоднородность структуры сплава Fe-25Cr-35Ni-C-Nb-Ti в литом состоянии проявляется не только в дендритной ликвации химических элементов состава в $\gamma$-фазе, но и в поликристаллическом строении карбидных фаз. Включения карбидов в структуре сплава - многофазные образования, не- однородные по химическому составу и кристаллическому строению. Частица карбида ниобия может состоять из нескольких кристаллов разной модификации ( $\left.\mathrm{NbC}, \mathrm{Nb}_{2} \mathrm{C}, \mathrm{Nb}_{6} \mathrm{C}_{5}\right)$, внутри которой может находиться карбонитрид титана $\operatorname{Ti}(\mathrm{CN})$.

Природа формирования кластеров карбидных фаз в структуре литых сплавов системы Fe-CrNi-C-Nb-Ti связана с характерными особенностями процесса их кристаллизации в условиях повышенной ликвации углерода и легирующих элементов. Средняя скорость охлаждения при статическом литье стандартных образцов толщиной 40 мм, используемых в работе для анализа структуры сплава, составляет $V_{\text {охл }} \approx 1 \mathrm{~K} / \mathrm{c}$, а в интервале температур $1350-800{ }^{\circ} \mathrm{C}-$ в 5-8 раз ниже. Длительность нахождения сплава при температурах $1350-800{ }^{\circ} \mathrm{C}$ при охлаждении составляет более 2000 с. Этого времени достаточно, чтобы на межфазных границах возникли высокие напряжения вследствие различия коэффициентов линейного расширения $\gamma$-фазы и карбидов. Если при кристаллизации сплава в структуре 


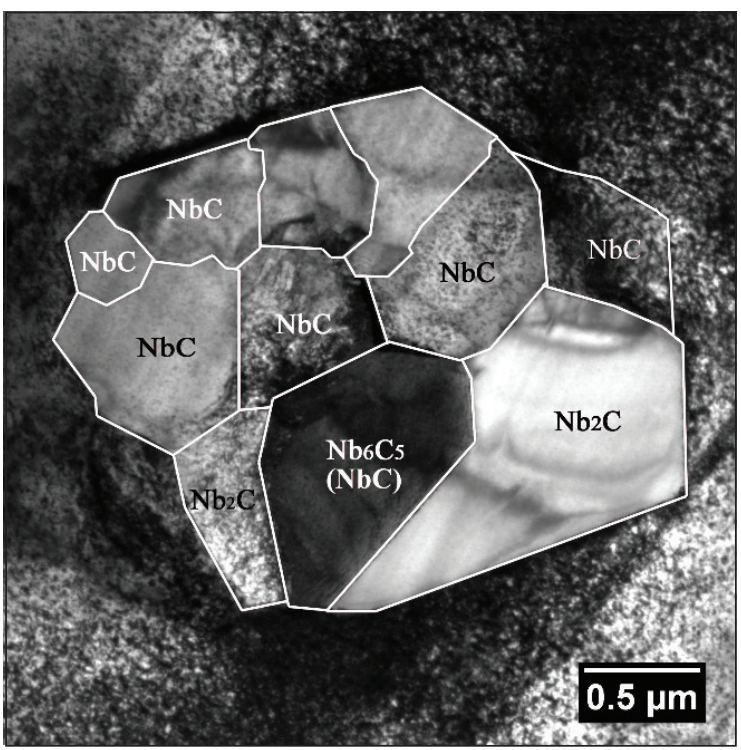

Рис. 9. Фазовый состав кластера карбида ниобия в литом сплаве $\left(\mathrm{Nb}_{2} \mathrm{C}-\right.$ кристаллы 1 и 11 на рис. 5). ПЭМ

образуется монокристалл карбида ниобия, то при последующем охлаждении движущая сила формирования из него поликристалла определяется различием средних коэффициентов термического сжатия фаз. В интервале температур $1350-100{ }^{\circ} \mathrm{C}$ их средние значения составляют: для $\gamma$-фазы $-20 \cdot 10^{-6} \mathrm{~K}^{-1}$, для карбида ниобия $7 \cdot 10^{-6} \mathrm{~K}^{-1}$. Модуль упругости жаропрочных сплавов $\mathrm{Fe}-\mathrm{Cr}-\mathrm{Ni}$ при температурах 20 и $1100{ }^{\circ} \mathrm{C}$ составляет соответственно примерно 180 и 70 ГПа [37]. Количественная оценка показывает, что при охлаждении от температуры солидус $\left(T_{\text {sol }} \approx\right.$ $\approx 1350{ }^{\circ} \mathrm{C}$ ) до $20{ }^{\circ} \mathrm{C}$ литая заготовка сплава сокращается по сравнению с исходным размером вблизи $T_{\text {sol }}$ на величину $1330 \times 20 \times 10^{-6}=0,026=$ $=2,6 \%$. При этом размер частиц карбидов ниобия сокращается на $0,9 \%$, т.е. в $2-3$ раза меньше. В результате охлаждающаяся матрица сжимает упруго или даже деформирует частицы карбидов в структуре сплава. Это может привести к фрагментации карбидных частиц и образованию поликристаллического кластера, состоящего из нескольких кристаллов.

Оценка уровня напряжений, возникающих в литом сплаве $\mathrm{Fe}-25 \mathrm{Cr}-35 \mathrm{Ni}-\mathrm{C}-\mathrm{Nb}-\mathrm{Ti}$ при первичном охлаждении, может быть проведена с учетом экспериментальной температурной зависимости величины его условного предела текучести $\sigma_{0,2}$ и модуля нормальной упругости $E$. Модуль нор- мальной упругости практически линейно повышается от 100 до 160 ГПа в интервале температур $1000 \rightarrow 20{ }^{\circ} \mathrm{C}$. Условный предел текучести повышается разным темпом в двух интервалах температур: в интервале $1000 \rightarrow 600{ }^{\circ} \mathrm{C} \sigma_{0,2}$ повышается от 90 до $250 \mathrm{MПа;} \mathrm{в} \mathrm{интервале} 600 \rightarrow 20^{\circ} \mathrm{C}$ - от 250 до 300 МПа. Таким образом, при температурах ниже $600{ }^{\circ} \mathrm{C}\left(T_{\text {пл }} / T \approx 0,5\right)$ сплав практически не упрочняется, следовательно, и его предел пропорциональности $\sigma_{0,05}$ остается практически неизменным. Тем не менее температурные напряжения, определяемые неравномерной усадкой по сечению заготовки (между поверхностью и центром), при охлаждении сплава непрерывно возрастают в соответствии с накапливаемой деформацией. Эта деформация определяется средним соотношением $\Delta l \approx l \alpha \Delta T$, где $\alpha-$ коэффициент термического расширения (при охлаждении сжатия) сплава. Общую величину термических напряжений можно оценить по соотношению $\sigma=(\Delta l / l) E(T)$, которое включает две составляющие. Первая - предел пропорциональности $\sigma_{0,05}$, вызывающий переменную пластическую деформацию. Вторая - напряжения $\Delta \sigma$, вызывающие локальную и общую пластическую деформацию заготовки сплава при охлаждении. Таким образом, общая величина напряжений, возникающих при охлаждении сплава, $-\sigma=\sigma_{0,05}+\Delta \sigma$, где $\Delta \sigma-$ превышение действующих термических напряжений над пределом пропорциональности. Поскольку в сплавах $\mathrm{Fe}-25 \mathrm{Cr}-35 \mathrm{Ni}-\mathrm{C}-\mathrm{Nb}-\mathrm{Ti}$ матричная фаза составляет более 90 \% (объемн.) и является непрерывной структурной составляющей, а частицы карбидных фаз имеют малый размер (менее 10 мкм) и занимают в структуре 5-8 \% (объемн.), именно матричная $\gamma$-фаза служит источником переменных во времени напряжений. В матрице действуют растягивающие напряжения, а в карбидах, имеющих более высокий модуль упругости, сжимающие. При отсутствии выраженной межфазной границы между $\gamma$-фазой и карбидом величина этих напряжений соответствует пределу пропорциональности $\gamma$-фазы ( $\left.\sigma \approx \sigma_{0,05}\right)$, который оценочно равен $\sigma_{0,05} \approx 0,0005 E(T) \approx 50-80$ МПа при охлаждении сплава в интервале температур $1000 \rightarrow 20^{\circ} \mathrm{C}$. В силу того, что предел текучести сплава $\mathrm{Fe}-25 \mathrm{Cr}-35 \mathrm{Ni}$ $\mathrm{C}-\mathrm{Nb}$-Ti в высокотемпературной области этого 
интервала составляет 90 МПа, возникающие при охлаждении напряжения могут вызвать фрагментацию монокристалла карбида ниобия.

Одна из существенных проблем достоверной оценки величины действующих напряжений сжатия карбида ниобия матрицей при охлаждении сплава - неопределенность состояния границы раздела между этими фазами. Применение химического травления или электрополировки образцов при анализе структуры сплавов вызывает трансформацию границы раздела фаз в зоны повышенной травимости. Корректный рельеф межфазной границы может быть изучен методами атомно-силовой микроскопии или 3D-изображений структуры сплава без травления. Однако авторы не нашли публикаций с такими изображениями структуры границы «карбид ниобия - $\gamma$-фаза». Возможная причина их отсутствия - технические сложности, связанные с малыми размерами частиц карбида ниобия, их изолированным расположением и малым объемным количеством в матрице $\left(\mathrm{Nb}_{m} \mathrm{C}_{n} / \gamma\right.$-фаза $\approx 1,5 / 90$ объемн. \%). В настоящей работе строение межфазной границы карбид/ аустенит было оценено на основе подобия структурного состояния границ $\mathrm{Nb}_{m} \mathrm{C}_{n} / \gamma$-фаза и $\mathrm{Cr}_{m} \mathrm{C}_{n} / \gamma$-фаза. Эти карбидные фазы имеют близкие значения таких физических характеристики, как модуль упругости, коэффициент термического расширения (сжатия) и др. Однако отличительной особенностью карбида хрома является образование эвтектики с $\gamma$-фазой. Соотношение фаз в эвтектике $\left(\mathrm{Cr}_{m} \mathrm{C}_{n}+\gamma\right)$ состав-

a)

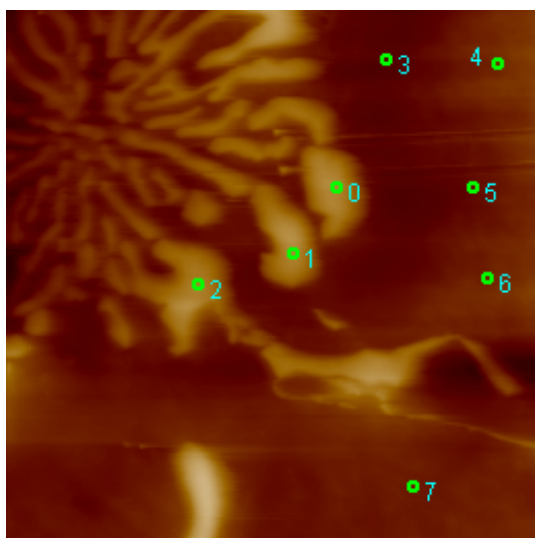

ляет $\mathrm{Cr}_{m} \mathrm{C}_{n} / \gamma$-фаза $\approx 50 / 50$ объемн. \% (рис. $10, a$ ), что позволяет получить 3D-изображение и оценить топологию межфазной границы (рис. 10,б).

Для изучения состояния межфазной границы $\mathrm{Cr}_{m} \mathrm{C}_{n} / \gamma$-фаза применяли наноиндентер Hysitron TI 750 UBI. Полученное таким способом 3D-изображение (рис. 10,б) показывает, что существует непрерывная связь на границе кристаллических решеток карбида и аустенита. Видно также, что частица карбида выступает над аустенитной матрицей примерно на 200 нм. Это позволяет утверждать, что карбид до приготовления шлифа был сжат и расширился после удаления части металла образца. Деформация $h$ по отношению к размеру сечения $l$ (в соответствии с размерной сеткой рис. 10,б) с учетом пластинчатой формы карбида (рис. $10, a$ ) составила $h / l \approx$ $0,2 / 10=0,02=2 \%$.

Чтобы подтвердить предположение о влиянии термических напряжений, возникающих в сплаве при охлаждении, на поликристаллическое строение частицы карбида ниобия в его структуре, была проведена термоциклическая обработка литого сплава. Режим термической обработки состоял в последовательном двукратном нагреве образцов сплава до температуры $1150{ }^{\circ} \mathrm{C}$ с выдержкой 1 ч и охлаждением на воздухе. На рис. 11 видно, что после термоциклирования фрагментация частиц карбида ниобия в структуре сплава становится более выраженной по сравнению с исходным литым состоянием (см. рис. 3). б)

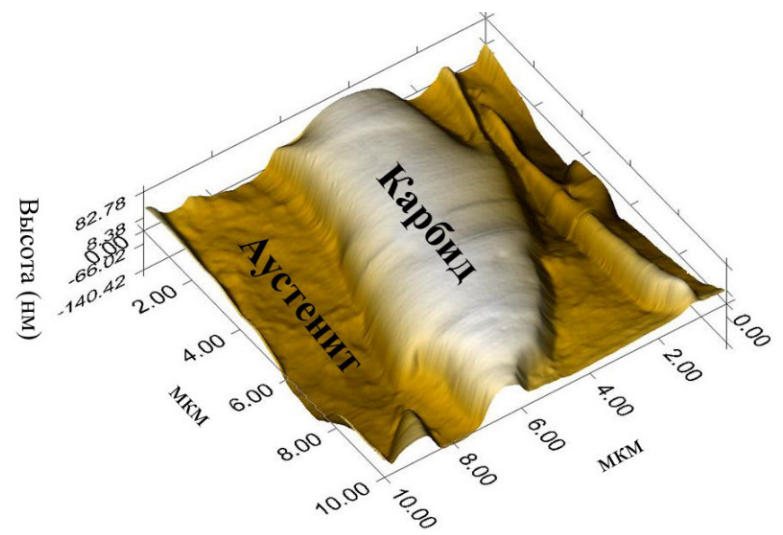

Рис. 10. Изображение эвтектики в структуре литого сплава: $a$ - общий характер структуры (область размером $30 \times 30$ мкм), $\sigma$ - рельеф поверхности в области межфазной границы карбид хрома/аустенит (3D-изображение поверхности образца без химического травления). Наноиндентер Hysitron TI 750 UBI 


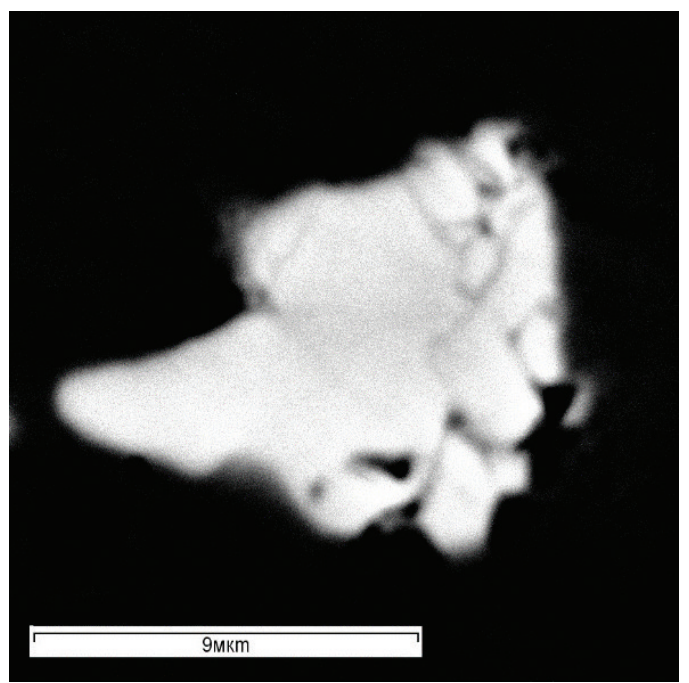

Рис. 11. Частица карбида ниобия в структуре сплава после термической обработки $1150{ }^{\circ} \mathrm{C}$ (1 ч, воздух $)$ и $+1150{ }^{\circ} \mathrm{C}$ (1 ч, воздух). СЭМ

Полученный результат эксперимента подтверждает, что механизм фрагментации частиц карбидов ниобия в структуре сплава Fe-25Cr$35 \mathrm{Ni}-\mathrm{C}-\mathrm{Nb}-\mathrm{Ti}$ связан с различием значений коэффициентов термического расширения фаз. Это объясняет поликристаллический характер карбидов, однако не объясняет их полиморфизма. Можно предположить две причины образования в структуре сплава частиц карбидов ниобия, состоящих из кристаллов с различным типом кристаллической решетки: 1) термические напряжения, возникающие на межфазных границах карбид/аустенит; 2) образование субмикронных доменов с разным кристаллическим строением в частице первичного карбида при кристаллизации расплава.

Первая из них связана со значительными термическими напряжениями, возникающими на межфазных границах в структуре сплава при первичном охлаждении слитка. В результате этого карбиды находятся под действием сжимающих напряжений, а $\gamma$-фаза - растягивающих. Такое распределение напряжений, по-видимому, при высоких температурах способствует диффузии углерода из пограничных кристаллов карбида ниобия в $\gamma$-фазу. Это может изменить соотношение ниобия и углерода в карбиде - с 1:1 в $\mathrm{NbC}$ до 2:1 в $\mathrm{Nb}_{2} \mathrm{C}$ - и привести к превращению $\mathrm{NbC} \rightarrow \mathrm{Nb}_{2} \mathrm{C}$. Характерно, что идентифицированные как $\mathrm{Nb}_{2}$ С кристаллы 1 и 11, входящие в кла- стер (рис. 9), имеют общую особенность - почти половина их периметра граничит с матричной $\gamma$-фазой, что определяет большую площадь диффузионной поверхности. Можно предположить, что обеднение граничных кристаллов кластера углеродом по сравнению с $\mathrm{NbC}$ происходит при высокой температуре за счет перехода углерода в матричную $\gamma$-фазу. Вероятно, этот процесс предшествует частичному растворению крупных первичных эвтектических карбидов ниобия по границам зерен $\gamma$-фазы и образованию мелких вторичных карбидов в матрице, наблюдавшихся в [15-16, 23].

Более детальное исследование структуры межфазной границы между кристаллами карбида ниобия и аустенитной матрицей показало присутствие на некоторых ее участках тонких включений, которые идентифицированы в ПЭМ как фаза $\mathrm{Cr}_{23} \mathrm{C}_{6}$ (рис. 12). Образование на межфазной границе тонких прослоек карбида хрома толщиной 10-30 нм можно считать подтверждением диффузии углерода из карбида ниобия в матрицу.

Подобные тонкие прослойки фазы, обогащенной хромом и углеродом, наблюдали на границе «карбид хрома/аустенит» в сплавах исследуемого типа в [20, 38, 39]. В [20] они идентифицированы в литом сплаве $\mathrm{Fe}-25 \mathrm{Cr}-33 \mathrm{Ni}-$ $1 \mathrm{Nb}-0,4 \mathrm{C}$ как карбид $\mathrm{Cr}_{7} \mathrm{C}_{3}$. В [38] и [39] они были обнаружены, соответственно, в сплаве $\mathrm{Fe}-20 \mathrm{Cr}-33 \mathrm{Ni}-2 \mathrm{Nb}-0,4 \mathrm{C}$ и в малоуглеродистом (0,13 масс. \% C) сплаве Fe-25Cr-35Ni, модифицированном $\mathrm{Nb}, \mathrm{Ti}, \mathrm{Zr}$, после старения 1000 ч при $900{ }^{\circ} \mathrm{C}$ и идентифицированы как карбид $\mathrm{Cr}_{23} \mathrm{C}_{6}$. По этой причине в [20] было сделано заключение, что тонкие включения $\mathrm{Cr}_{23} \mathrm{C}_{6}$ образуются в структуре сплава за счет перехода $\mathrm{Cr}_{7} \mathrm{C}_{3} \rightarrow \mathrm{Cr}_{23} \mathrm{C}_{6}$ при высокотемпературной выдержке. Однако результаты нашего исследования показывают, что в структуре сплава Fe$25 \mathrm{Cr}-35 \mathrm{Ni}-\mathrm{C}-\mathrm{Nb}-\mathrm{Ti}$ в литом состоянии на границе карбида ниобия и $\gamma$-фазы может присутствовать тонкая прослойка карбида хрома $\mathrm{Cr}_{23} \mathrm{C}_{6}$, образующаяся при первичном охлаждении в твердом состоянии, что согласуется с данными [38, 39].

Оценочный расчет кинетики роста прослойки карбида $\mathrm{Cr}_{23} \mathrm{C}_{6}$ на межфазной границе « $\mathrm{NbC} /$ матрица» при первичном охлаждении литого 


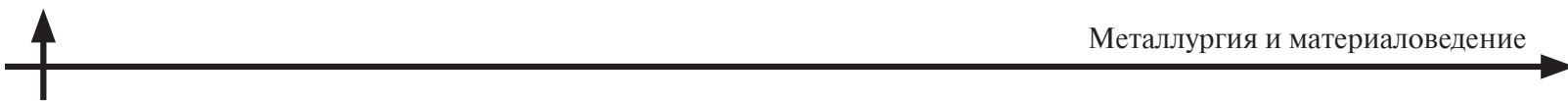

a)

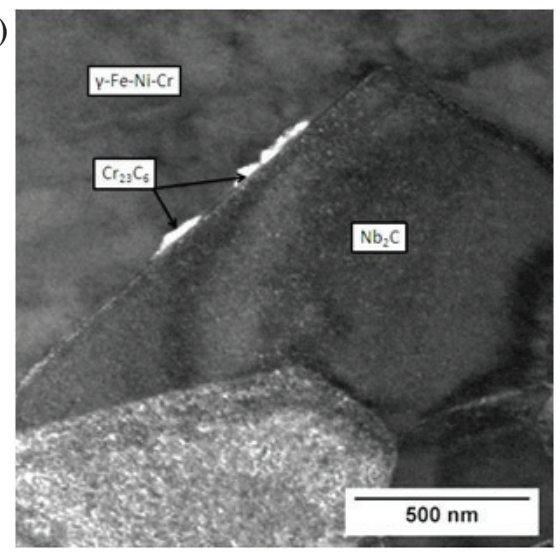

б)

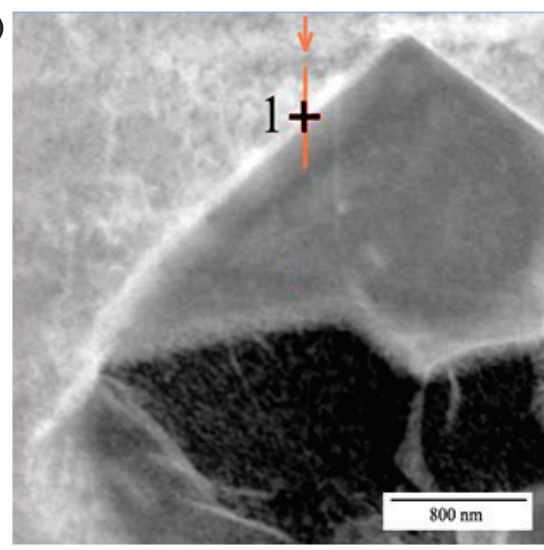

в)

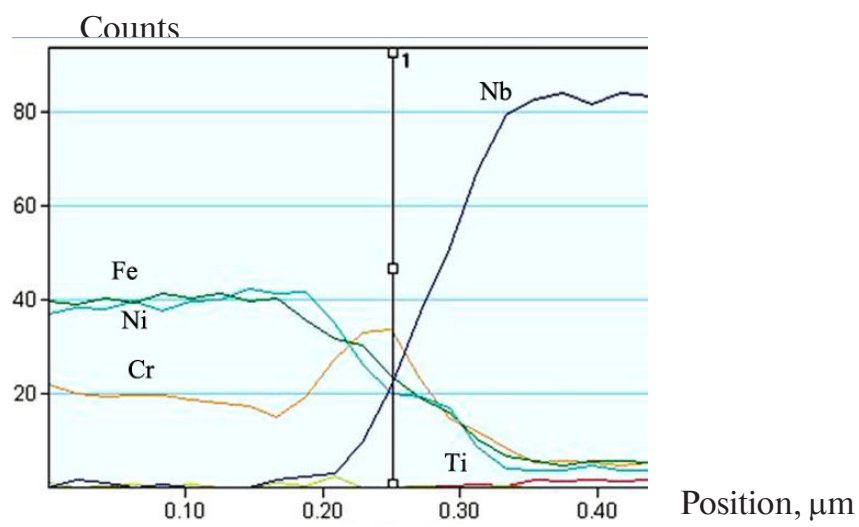

Рис. 12. Микроструктура и энергодисперсионный рентгеноспектральный микроанализ литого сплава: $a$ - темнопольное изображение структуры; $\sigma$ - изображение структуры с траекторией анализа; в - профиль распределения элементов по траектории анализа. ПЭМ

сплава можно выполнить на основе баланса концентрации лимитирующего элемента. В соответствии с [10] поток вещества из неограниченной матрицы к растущей фазе равен

$$
q(\tau)=\left(C_{\mathrm{o}}-C_{\text {гр }}\right) \frac{\sqrt{D}}{\sqrt{\pi \tau}} .
$$

В этом случае формула для расчета размера частицы, растущей на межфазной границе, имеет вид

$$
L=\frac{\left(C_{\mathrm{o}}-C_{\Gamma \mathrm{p}}\right)}{\left(C_{\mathrm{\phi}}-C_{\Gamma \mathrm{p}}\right)} \frac{2}{\sqrt{\pi}} \sqrt{D \tau}=k \sqrt{D \tau},
$$

где $C_{0}, C_{\phi}, C_{\text {гр }}$ - концентрации элемента соответственно в среднем по матрице, в новой фазе и в матрице на границе раздела с новой фазой; $D$ - коэффициент диффузии; $\tau-$ время. Учитывая, что максимальный размер частицы карбида хрома $\mathrm{Cr}_{23} \mathrm{C}_{6}$ на межфазной границе карбид « $\mathrm{NbC} /$ матрица» экспериментально определен равным $L \approx 30$ нм, оценим процесс диффузии, лимитируемый отдельно углеродом и хромом.

1. Рассмотрим односторонний подвод углерода со стороны карбида ниобия $\mathrm{NbC}$. Концентрация углерода в карбиде ниобия $-C_{0}=50$ ат. \%; концентрация углерода в $\gamma$-фазе на границе с карбидом ниобия, где образуется пограничный карбид хрома, составляет $C_{\text {гр }} \leqslant 0,4$ ат. $\%(\leqslant 0,1$ масс. \%); концентрация углерода в карбиде хрома $-C_{\phi}=21,7$ ат. \%. Таким образом, из формулы (2) следует

$$
k_{C}=\frac{2}{\left.\sqrt{\pi\left(C_{\mathrm{o}}-C_{г \mathrm{p}}\right) /(} C_{\mathrm{\phi}}-C_{г \mathrm{p}}\right)}=2,58 .
$$

Учитывая, что $D^{\mathrm{C}}{ }_{\mathrm{NbC}}=7,6 \exp (-88,2$ ккал/ моль/RT) см²/c [40] и температура плавления $\mathrm{NbC}$ равна $3600^{\circ} \mathrm{C}$, получаем, например при температуре $1150{ }^{\circ} \mathrm{C}(1423 \mathrm{~K})$ :

$D_{\mathrm{NbC}}^{\mathrm{C}}=7,6 \exp (-88,2 \cdot 1000 / 2 \cdot 1423) \approx 2,6 \cdot 10^{-13} \mathrm{~cm}^{2} / \mathrm{c}$. 
Следовательно, для $1150{ }^{\circ} \mathrm{C}$ время роста частицы карбида хрома толщиной $L=30$ нм, лимитированное диффузией углерода через карбид ниобия к образующейся частице карбида хрома, составляет

$\tau \approx L^{2} /\left[\left(k_{c}\right)^{2} D_{\mathrm{NbC}}^{\mathrm{C}}\right]=32 \cdot 32 \cdot 10^{-14} /(2,58)^{2} \cdot 2,6 \cdot 10^{-13} \approx 15 \mathrm{c}$.

2. Рассмотрим диффузию хрома из $\gamma$-фазы в образующийся карбид хрома, принимая $D^{\mathrm{Cr}} \approx$ $\approx 10^{-12} \mathrm{~cm}^{2} / \mathrm{c}$ [10]. По экспериментальным данным рентгеноспектрального микроанализа концентрация хрома в карбиде ниобия $\mathrm{NbC}$ составляет $C_{\text {гр }} \approx 1$ ат. $\%$, а средняя в матрице $-C_{0} \approx 25$ ат. \%; концентрация хрома в карбиде $\mathrm{M}_{23} \mathrm{C}_{6}-C_{\phi}=79,3$ ат. \%. Тогда из формулы (2) следует

$$
k_{\mathrm{Cr}}=\frac{2}{\sqrt{\pi\left(C_{\mathrm{o}}-C_{\text {гр }}\right) /\left(C_{\text {क }}-C_{\text {гр }}\right)}}=0,346 .
$$

Следовательно, для $1150{ }^{\circ} \mathrm{C}$ время роста частицы карбида хрома толщиной $L=30$ нм, лимитированное диффузией хрома через матрицу к образующейся частице карбида хрома, составляет

$$
\tau \approx L^{2} /\left[\left(k_{\tilde{\mathrm{Nr}}}\right)^{2} D_{\gamma}^{\mathrm{Cr}}\right] \approx 85 \mathrm{c} .
$$

Таким образом, для образования карбида $\mathrm{Cr}_{23} \mathrm{C}_{6}$ на границе «NbC/аустенит» при $1150{ }^{\circ} \mathrm{C}$ время диффузионного накопления хрома из $\gamma$-фазы в 5 раз больше, чем время накопления углерода из карбида ниобия. Результаты расчета показывают, что процесс образования межфазной прослойки карбида $\mathrm{Cr}_{23} \mathrm{C}_{6}$ существенно лимитируется диффузией хрома из $\gamma$-фазы (рис. 13). Однако, даже учитывая, что скорость роста частицы карбида, рассчитываемая из (2) как

$$
\frac{d L}{d \tau}=v=0,5 k \sqrt{D} \frac{1}{\sqrt{\tau}},
$$

резко уменьшается при понижении температуры, длительность нахождения сплава при температурах $1350-800^{\circ} \mathrm{C}(\sim 2000$ с $)$ при первичном охлаждении достаточна для образования частицы карбида толщиной 30 нм.

Второй причиной полиморфного строения карбидов ниобия в сплавах $\mathrm{Fe}-25 \mathrm{Cr}-35 \mathrm{Ni}-\mathrm{C}-\mathrm{Nb}-$ Ті может быть изначальное образование субмикронных доменов с разным кристаллическим строением в частице первичного карбида при

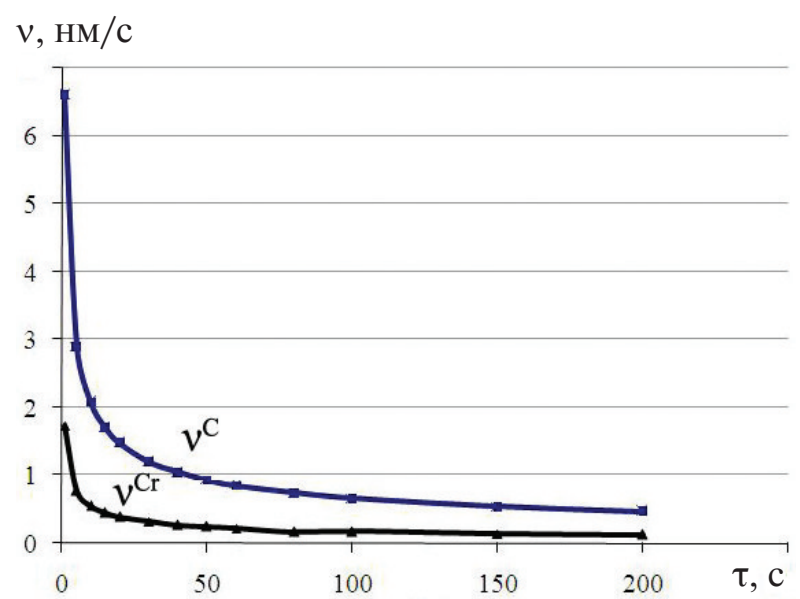

Рис. 13. Зависимость скорости роста карбида хрома $\mathrm{Cr}_{23} \mathrm{C}_{6}$ от времени при $1150{ }^{\circ} \mathrm{C}$ для процесса, лимитированного диффузией углерода $\left(v^{\mathrm{C}}\right)$ и хрома $\left(v^{\mathrm{Cr}}\right)$

кристаллизации расплава. Это возможно из-за стохастического процесса образования твердых фаз в сплаве и химической неоднородности разбавленного расплава, содержащего 0,50 ат. \% ниобия и 2,0 ат. \% углерода, а также из-за полиморфизма и особенностей кристаллического строения карбида ниобия. Выяснение этого вопроса требует дальнейшего изучения.

\section{Заключение}

Результаты исследования показывают, что упрочняющие частицы карбида ниобия в структуре литого жаропрочного сплава $\mathrm{Fe}-25 \mathrm{Cr}-35 \mathrm{Ni}-$ $0,4 \mathrm{C}-\mathrm{Nb}-\mathrm{Ti}$ преимушественно являются многофазными поликристаллическими кластерами, неоднородными по химическому составу и кристаллическому строению. В центре кластера может находиться карбонитрид титана $\operatorname{Ti}(\mathrm{CN})$, вокруг которого располагаются кристаллы карбида ниобия. Эти кристаллы имеют разные модификации - $\mathrm{NbC}, \mathrm{Nb}_{2} \mathrm{C}, \mathrm{Nb}_{6} \mathrm{C}_{5}$ соответственно с кубической, орторомбической, моноклинной кристаллическими решетками. Поликристаллический характер карбидов, вероятно, связан со значительными термическими напряжениями, возникающими на межфазных границах в структуре сплава при первичном охлаждении слитка. При охлаждении сплава от температуры ликвидус карбиды ниобия испытывают значительные напряжения сжатия, поскольку матричная $\gamma$-фаза имеет коэффициент термического 
сжатия (расширения) примерно в три раза больший, чем первичные карбиды ниобия. Характерно, что при повторных циклах «нагрев-охлаждение» границы между кристаллами в кластере становятся грубее. Причины полиморфизма кластера карбида менее понятны. Возможно, при высоких температурах происходит частичное растворение карбида с поверхности, сопровождающееся переходом углерода в матричную фазу и, как следствие, изменением соотношения ниобия и углерода в карбиде. Этот процесс термодинамически обоснован, поскольку $\gamma$-фаза обеднена углеродом по сравне- нию с пределом растворимости при первичной эвтектической кристаллизации с образованием устойчивых карбидов. Можно также предположить, что домены с разным кристаллическим строением в частице карбида ниобия образуются при кристаллизации расплава. Механизм образования таких карбидов при кристаллизации и их последующей трансформации в процессах нагрева и выдержки при термической обработке и эксплуатации требует отдельного исследования. В дальнейшем представляет интерес анализ этого механизма на основе положений структурной и геометрической кристаллографии [41-43].

\section{СПИСОК ЛИТЕРАТУРЫ}

1. Garbiak M., Jasinski W., Piekarski B. Materials for Reformer Furnace Tubes. History of Evolution // Archives Of Foundry Engineering. 2011. Vol. 11, Spesial Issue 2. P. 47-52.

2. Bonaccorsi L., Guglielmino E., Pino E., Servetto C., Sili A. Damage analysis in Fe-Cr-Ni centrifugally cast alloy tubes for reforming furnaces // Eng. Fail. Anal. 2014. Vol. 36. P. 65-74.

3. Ilman M.N., Kusmono. Analysis of material degradation and life assessment of $25 \mathrm{Cr}-38 \mathrm{Ni}$-Mo-Ti wrought alloy steel (HPM) for cracking tubes in an ethylene plant // Eng. Fail. Anal. 2014. Vol. 42. P. 100-108.

4. Tawancy H.M., Ul-Hamid A., Mohammed A.I., Abbas N.M. Effect of materials selection and design on the performance of an engineering product - An example from petrochemical industry // Materials \& Design. 2007. Vol. 28, Is. 2. P. 686-703. DOI 10.1016/j.matdes.2005.07.003.

5. Kaya A.A., Krauklis P., Young D.J. Microstructure of HK40 alloy after high-temperature service in oxidizing/carburizing environment: I. Oxidation phenomena and propagation of a crack // Mater. Char. 2002. Vol. 49, № 1. P. 11-21.

6. Kaya A.A. Microstructure of HK40 alloy after hightemperature service in oxidizing/carburizing environment: II. Carburization and carbide transformations // Mater. Char. 2002. Vol. 49, № 1. P. 23-34.

7. De Almeida L.H., Ribeiro A.F., Le May I. Microstructural characterization of modified $25 \mathrm{Cr}-35 \mathrm{Ni}$ centrifugally cast steel furnace tubes // Materials Characterization. 2003. Vol. 49. № 3. P. 219-229.

8. Kenik E.A., Maziasz P.J., Swindeman R.W., Cervenka J., May D. Structure and phase stability in cast modified-HP austenite after long-term ageing // Scripta materialia. 2003. Vol. 49. № 2. P. 117-122.

9. Рудской А.И., Орыщенко А.С., Кондратьев С.Ю., Анастасиади Г.П., Фукс М.Д., Петров С.Н. Особенности структуры и длительная прочность литого жаропрочного сплава 45Х26Н33С2Б2 // Металловеде- ние и термическая обработка металлов. 2013. № 4 (694). С. 42-47.

10. Рудской А.И., Анастасиади Г.П., Кондратьев С.Ю., Орыщенко А.С., Фукс М.Д. Влияние фактора числа электронных вакансий на кинетику образования, роста и растворения фаз при длительных высокотемпературных выдержках жаропрочного сплава $0.45 \mathrm{C}-26 \mathrm{Cr}-33 \mathrm{Ni}-2 \mathrm{Si}-2 \mathrm{Nb} / /$ Физика металлов и металловедение. 2014. Т. 115, № 1. С. 3-13.

11. Sustaita-Torres I.A., Haro-Rodrigues S., Guerrero-Mata M.P., De La Garza M., Valdes E., DeschauxBeaume F., Colas R. Aging of cast $35 \mathrm{Cr}-45 \mathrm{Ni}$ heat resistant alloy // Materials Chemistry and Physics. 2012. Vol. 133. P. $1018-1023$.

12. Monobe L.S., Schőn C.G. Microstructural and fractographic investigation of a centrifugally cast $20 \mathrm{Cr} 32 \mathrm{Ni}+\mathrm{Nb}$ alloy tube in the as caśt and aged states // Journal of Materials Research and Technology. 2013. Vol. 2. № 2. P. 195-201.

13. Wang W.Z., Xuan F.Z., Wang Z.D., Liu C.J. Effect of overheating temperature on the microstructure and creep behavior of HP40Nb alloy // Materials and Design. 2011. Vol. 32. P. 4010-4016.

14. Borjali S., Allahkaram S.R., Khosravi H. Effects of working temperature and carbon diffusion on the microstructure of high pressure heat-resistant stainless steel tubes used in pyrolysis furnaces during service condition // Materials and Design. 2012. Vol. 34. P. 65-73.

15. Рудской А.И., Орыщенко А.С., Кондратьев С.Ю., Анастасиади Г.П., Фукс М.Д. Механизм и кинетика фазовых превращений в жаропрочном сплаве 45Х26Н33С2Б2 при длительных высокотемпературных выдержках. Часть $1 / / \mathrm{Me}-$ талловедение и термическая обработка металлов. 2014. № 1 (703). С. 3-8.

16. Рудской А.И., Кондратьев С.Ю., Анастасиади Г.П., Орыщенко А.С., Фукс М.Д. Механизм и кинетика фазовых превращений в жаропрочном сплаве 45Х26Н33С2Б2 при длительных высокотемпературных 
выдержках. Часть 2 // Металловедение и термическая обработка металлов. 2014. № 3 (705). С. 12-19.

17. Рудской А.И., Кондратьев С.Ю., Анастасиади Г.П., Орыщенко А.С., Фукс М.Д., Петров С.Н. Трансформация структуры жаропрочного сплава $0,45 \mathrm{C}-26 \mathrm{Cr}-33 \mathrm{Ni}-2 \mathrm{Si}-2 \mathrm{Nb}$ при длительной высокотемпературной выдержке // Металловедение и термическая обработка металлов. 2013. № 10 (700). C. 7-14.

18. Piekarski B. Effect of $\mathrm{Nb}$ and Ti additions on microstructure and identification of precipitates in stabilized Ni-Cr cast austenitic steels // Materials Characterization. 2001. Vol. 47. P. 181-186.

19. De Almeida Soares G.D., De Almeida L.H., Da Silveira T.L., Le May I. Niobium additions in HP heat-resistant cast stainless steels // Materials Characterization. 1992. Vol. 29. Iss. 3. P. 387-396.

20. Buchanan K.G., Kral M.V. Crystallography and morphology of niobium carbide in as-cast HP-niobium reformer tubes // Metallurgical and Materials Transactions A. 2012. Vol. 43A. Is. 6. P. 1760-1769. DOI 10.1007/ s11661-011-1025-0.

21. Buchanan K.G., Kral M.V., Bishop C.M. Crystallography and morphology of MC carbides in niobium-titanium modified as-cast HP alloys // Metallurgical and Materials Transactions A. 2014. Vol. 45A. Is. 8. P. 3373-3385. DOI 10.1007/s11661-0142285-2.

22. Nunes F.C., De Almeida L.H., Dille J., Delplancke J.-L., Le May I. Microstructural changes caused by yttrium addition to NbTi-modified centrifugally cast HPtype stainless steels // Materials Characterization. 2007. Vol. 58. P. 132-42.

23. Кондратьев С.Ю., Пташник А.В., Анастасиади Г.П., Петров С.Н. Анализ превращений карбидных фаз в сплаве $25 \mathrm{Cr} 35 \mathrm{Ni}$ методом количественной электронной микроскопии // Металловедение и термическая обработка металлов. 2015. № 7(721). C. $36-43$.

24. Jingbo Y., Yimin G., Fang Y., Caiying Y., Zhaozhong Y., Dawei Y., Shengqiang M. Effect of tungsten on the microstructure evolution and mechanical properties of yttrium modified HP40Nb alloy // Mater. Sci. Eng. 2011. Vol. 529. P 361-369.

25. Sourmail T. Precipitates in creep resistant austenitic stainless steels // Mater. Sci. Technol. Vol. 17. № 1. P. 1-14.

26. Рыбин В.В., Рубцов А.С., Нестерова Е.В. Метод одиночных рефлексов (ОР) и его применение для электронномикроскопического анализа дисперсных фаз // Заводская лаборатория. 1982. № 5. C. $16-21$.

27. Родионова И.Г., Зайцев А.И., Шапошников Н.Г., Чиркина И.Н., Покровский А.М., Немтинов А.А., Мишнев П.А., Кузнецов В.В. Влияние химического состава и параметров производства на формирование наноструктурной составляющей и комплекса свойств высокопрочных низколегированных конструкционных сталей // Металлург. 2010. № 6. С. 33-39.

28. Mao Z., Chen W., Seidman D.N., Wolverton C. First-principles study of the nucleation and stability of ordered precipitates in ternary $\mathrm{Al}-\mathrm{Sc}-\mathrm{Li}$ alloys // Acta Materialia. 2011. Vol. 59. Iss. 8. P. 3012-3023.

29. Monachon C., Krug M.E., Seidman D.N., Dunand D.C. Chemistry and structure of core/double-shell nanoscale precipitates in $\mathrm{Al}-6.5 \mathrm{Li}-0.07 \mathrm{Sc}-0.02 \mathrm{Yb}$ (at.\%) // Acta Materialia. 2011. Vol. 59. Iss. 9. P. 3398-3409.

30. Formenti A., Eliasson A., Mitchell A., Fredriksson $\mathbf{H}$. Solidification sequence and carbide precipitation in Ni-base superalloys IN718, IN625 AND IN939 // High Temperature Materials and Processes. 2005. Vol. 24. Iss. 4. P. 239-258. DOI 10.1515/HTMP.2005.24.4.239.

31. Nunes F.C., Dille J., Delplancke J.-L., De Almeida L.H. Yttrium addition to heat-resistant cast stainless steel // Scripta Mater. 2006. Vol. 54. Iss. 9. P. 1553-1556.

32. Konno T.J., Miura E., Tanaka A., Hanada Sh. A TEM study on the simicoherent precipitates in a $\mathrm{Nb}-$ 19\% Mo alloy // Acta Materialia. 2005. Vol. 53. Iss. 6. P. 1783-1789.

33. Billingham J., Bell P.S., Lewis M.H. Vacancy short-range order in substoichiometric transition metal carbides and nitrides with the $\mathrm{NaCl}$ structure. I. Electron diffraction studies of short-range ordered compounds // Acta Crystallographica Section A. 1972. Vol. A28. N 6. P. 602-606. DOI 10.1107/S0567739472001524.

34. Landesman J.P., Christensen A.N., De Novion C.H., Lorenzelli N., Convert P. Order-disorder transition and structure of the ordered vacancy compound Nb6C5: powder neutron diffraction studies // Journal of Physics C: Solid State Physics. 1985. Vol. 18. № 4. P. 809-824.

35. Kesri R., Hamar-Thibault S. Structures ordonnees a longue distance dans les carbures mc dans les fonts // Acta Metallurgica. 1988. Vol. 36. Iss. 1. P. 149-166.

36. Gusev A.I., Rempel A.A. Order-disorder phase transition channel in niobium carbide // Physica Status Solidi (a). 1986. Vol. 93. Is. 1. P. 71-80.

37. Steel Castings Handbook. Supplement 9. High Alloy Data Sheets. Heat Series / Ohio: Steel Founder's Society of America, 2004. 60 p.

38. Ibanez R.A.P., De Almeida Soares G.D., De Almeida L.H., Le May I. Effects of Si content on the microstructure of modified-HP austenitic steels // Mater. Charact. 1993. Vol. 30. P. 243-249.

39. Caballero F.G., Imizcoz P., Lopez V., Alvarez L.F., and Garcia de Andres C. Use of titanium and zirconium in centrifugally cast heat resistant steel // Materials Science and Technology. 2007. Vol. 23. Iss. 5. P. 528-534.

40. Brizes Wm.F., Cadoff L.H., Tobin J.M. Carbon diffusion in the carbides of niobium // Journal of Nuclear Materials. 1966. Vol. 20, Is. 1. P. 57-67. 


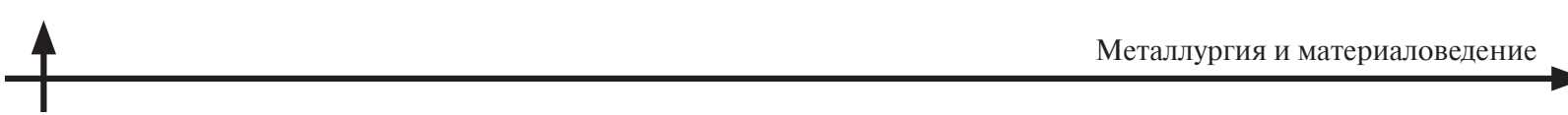

41. Talis A., Kraposhin V. Finite noncrystallographic groups, 11-vertex triangulated clusters, and polymorphic transformations in metals // Acta Cryst. 2014. Vol. A70. P. 616-625.

42. Kondrat'ev S.Yu, Kraposhin V.S., Anastasiadi G.P., Talis A.L. Experimental observation and crystallographic description of $\mathrm{M} 7 \mathrm{C} 3$ carbide transformation in
Fe-Cr-Ni-C HP type alloy // Acta Materialia. 2015. Vol. 100. P. 275-281.

43. Крапошин В.С., Талис А.Л., Демина Е.Д., Зайцев А.И. Кристаллогеометрический механизм срастания шпинели и сульфида марганца в комплексное неметаллическое включение // Металловедение и термическая обработка металлов. 2015. № 7(721). С. $4-12$

\section{REFERENCES}

1. Garbiak M., Jasinski W., Piekarski B. Materials for Reformer Furnace Tubes. History of Evolution. Archives Of Foundry Engineering. 2011. Vol. 11, Spesial Issue 2. P. 47-52.

2. Bonaccorsi L., Guglielmino E., Pino E., Servetto C., Sili A. Damage analysis in $\mathrm{Fe}-\mathrm{Cr}-\mathrm{Ni}$ centrifugally cast alloy tubes for reforming furnaces. Eng. Fail. Anal. 2014. Vol. 36. P. 65-74.

3. Ilman M.N., Kusmono. Analysis of material degradation and life assessment of $25 \mathrm{Cr}-38 \mathrm{Ni}-\mathrm{Mo}$-Ti wrought alloy steel (HPM) for cracking tubes in an ethylene plant. Eng. Fail. Anal. 2014. Vol. 42. P. 100-108.

4. Tawancy H.M., Ul-Hamid A., Mohammed A.I., Abbas N.M. Effect of materials selection and design on the performance of an engineering product - An example from petrochemical industry. Materials \& Design. 2007. Vol. 28, Is. 2. P. 686-703. DOI 10.1016/j.matdes.2005.07.003.

5. Kaya A.A., Krauklis P., Young D.J. Microstructure of HK40 alloy after high-temperature service in oxidizing/carburizing environment: I. Oxidation phenomena and propagation of a crack. Mater. Char. 2002. Vol. 49, № 1. P. 11-21.

6. Kaya A.A. Microstructure of HK40 alloy after hightemperature service in oxidizing/carburizing environment: II. Carburization and carbide transformations. $M a-$ ter. Char. 2002. Vol. 49, №1. P. 23-34.

7. De Almeida L.H., Ribeiro A.F., Le May I. Microstructural characterization of modified $25 \mathrm{Cr}-35 \mathrm{Ni}$ centrifugally cast steel furnace tubes. Materials Characterization. 2003. Vol. 49, № 3. P. 219-229.

8. Kenik E.A., Maziasz P.J., Swindeman R.W., Cervenka J., May D. Structure and phase stability in cast modified-HP austenite after long-term ageing. Scripta materialia. 2003. Vol. 49, № 2. P. 117-122.

9. Rudskoy A.I., Oryshchenko A.S., Kondratyev S.Yu., Anastasiadi G.P., Fuks M.D., Petrov S.N. Osobennosti struktury i dlitelnaya prochnost litogo zharoprochnogo splava 45Kh26N33S2B2. Metallovedeniye i termicheskaya obrabotka metallov. 2013. № 4 (694). S. 42-47.

10. Rudskoy A.I., Anastasiadi G.P., Kondratyev S.Yu., Oryshchenko A.S., Fuks M.D. Vliyaniye faktora chisla elektronnykh vakansiy na kinetiku obrazovaniya, rosta $\mathrm{i}$ rastvoreniya faz pri dlitelnykh vysokotemperaturnykh vyderzhkakh zharoprochnogo splava $0.45 \mathrm{C}-26 \mathrm{Cr}-33 \mathrm{Ni}-$
2Si-2Nb. Fizika metallov i metallovedeniye. 2014. T. 115. № 1. S. 3-13.

11. Sustaita-Torres I.A., Haro-Rodrigues S., GuerreroMata M.P., De La Garza M., Valdes E., Deschaux-Beaume F., Colas R. Aging of cast $35 \mathrm{Cr}-45 \mathrm{Ni}$ heat resistant alloy. Materials Chemistry and Physics. 2012. Vol. 133. P. 1018-1023.

12. Monobe L.S., Schőn C.G. Microstructural and fractographic investigation of a centrifugally cast $20 \mathrm{Cr} 32 \mathrm{Ni}+\mathrm{Nb}$ alloy tube in the' as caśt and aged states // Journal of Materials Research and Technology. 2013. Vol. 2, № 2. P. 195-201.

13. Wang W.Z., Xuan F.Z., Wang Z.D., Liu C.J. Effect of overheating temperature on the microstructure and creep behavior of HP40Nb alloy. Materials and Design. 2011. Vol. 32. P. 4010-4016.

14. Borjali S., Allahkaram S.R., Khosravi H. Effects of working temperature and carbon diffusion on the microstructure of high pressure heat-resistant stainless steel tubes used in pyrolysis furnaces during service condition. Materials and Design. 2012. Vol. 34. P. 65-73.

15. Rudskoy A.I., Oryshchenko A.S., Kondratyev S.Yu., Anastasiadi G.P., Fuks M.D. Mekhanizm i kinetika fazovykh prevrashcheniy $\mathrm{V}$ zharoprochnom splave 45Kh26N33S2B2 pri dlitelnykh vysokotemperaturnykh vyderzhkakh. Chast 1. Metallovedeniye i termicheskaya obrabotka metallov. 2014. № 1 (703). S. 3-8.

16. Rudskoy A.I., Kondratyev S.Yu., Anastasiadi G.P., Oryshchenko A.S., Fuks M.D. Mekhanizm i kinetika fazovykh prevrashcheniy $\mathrm{V}$ zharoprochnom splave 45Kh26N33S2B2 pri dlitelnykh vysokotemperaturnykh vyderzhkakh. Chast 2. Metallovedeniye i termicheskaya obrabotka metallov. 2014. № 3 (705). S. 12-19.

17. Rudskoy A.I., Kondratyev S.Yu., Anastasiadi G.P., Oryshchenko A.S., Fuks M.D., Petrov S.N. Transformatsiya struktury zharoprochnogo splava $0,45 \mathrm{C}-26 \mathrm{Cr}$ $-33 \mathrm{Ni}-2 \mathrm{Si}-2 \mathrm{Nb}$ pri dlitelnoy vysokotemperaturnoy vyderzhke. Metallovedeniye $i$ termicheskaya obrabotka metallov. 2013. № 10 (700). S. 7-14.

18. Piekarski B. Effect of $\mathrm{Nb}$ and Ti additions on microstructure and identification of precipitates in stabilized $\mathrm{Ni}-\mathrm{Cr}$ cast austenitic steels. Materials Characterization. 2001. Vol. 47. P. 181-186. 
19. De Almeida Soares G.D., De Almeida L.H., Da Silveira T.L., Le May I. Niobium additions in HP heat-resistant cast stainless steels. Materials Characterization. 1992. Vol. 29, Iss. 3. P. 387-396.

20. Buchanan K.G., Kral M.V. Crystallography and morphology of niobium carbide in as-cast HP-niobium reformer tubes. Metallurgical and Materials Transactions A. 2012. Vol. 43A. Is. 6. P. 1760-1769. DOI 10.1007/ s11661-011-1025-0.

21. Buchanan K.G., Kral M.V., Bishop C.M. Crystallography and morphology of MC carbides in niobium-titanium modified as-cast HP alloys. Metallurgical and Materials Transactions A. 2014. Vol. 45A. Is. 8. P. 3373-3385. DOI 10.1007/s11661-014-2285-2.

22. Nunes F.C., De Almeida L.H., Dille J., Delplancke J.-L., Le May I. Microstructural changes caused by yttrium addition to NbTi-modified centrifugally cast HPtype stainless steels. Materials Characterization. 2007. Vol. 58. P. 132-42.

23. Kondratyev S.Yu., Ptashnik A.V., Anastasiadi G.P., Petrov S.N. Analiz prevrashcheniy karbidnykh faz v splave $25 \mathrm{Cr} 35 \mathrm{Ni}$ metodom kolichestvennoy elektronnoy mikroskopii. Metallovedeniye i termicheskaya obrabotka metallov. 2015. № 7 (721). S. 36-43.

24. Jingbo Y., Yimin G., Fang Y., Caiying Y., Zhaozhong Y., Dawei Y., Shengqiang M. Effect of tungsten on the microstructure evolution and mechanical properties of yttrium modified HP40Nb alloy. Mater. Sci. Eng A. 2011. Vol. 529. P. 361-369.

25. Sourmail T. Precipitates in creep resistant austenitic stainless steels. Mater. Sci. Eng A. 2001. Vol. 17, № 1. P. $1-14$

26. Rybin V.V., Rubtsov A.S., Nesterova Ye.V. Metod odinochnykh refleksov (OR) i yego primeneniye dlya elektronnomikroskopicheskogo analiza dispersnykh faz. $\mathrm{Za}$ vodskaya laboratoriya. 1982. № 5. S. 16-21.

27. Rodionova I.G., Zaytsev A.I., Shaposhnikov N.G., Chirkina I.N., Pokrovskiy A.M., Nemtinov A.A., Mishnev P.A., Kuznetsov V.V. Vliyaniye khimicheskogo sostava i parametrov proizvodstva na formirovaniye nanostrukturnoy sostavlyayushchey i kompleksa svoystv vysokoprochnykh nizkolegirovannykh konstruktsionnykh staley. Metallurg. 2010. № 6. S. 33-39.

28. Mao Z., Chen W., Seidman D.N., Wolverton C. First-principles study of the nucleation and stability of ordered precipitates in ternary $\mathrm{Al}-\mathrm{Sc}-\mathrm{Li}$ alloys. Acta Materialia. 2011. Vol. 59, Iss. 8. P. 3012-3023.

29. Monachon C., Krug M.E., Seidman D.N., Dunand D.C. Chemistry and structure of core/double-shell nanoscale precipitates in $\mathrm{Al}-6.5 \mathrm{Li}-0.07 \mathrm{Sc}-0.02 \mathrm{Yb}$ (at.\%). Acta Materialia. 2011. Vol. 59, Iss. 9. P. 33983409 .

30. Formenti A., Eliasson A., Mitchell A., Fredriksson H. Solidification sequence and carbide precipitation in Ni-base superalloys IN718, IN625 AND IN939. High
Temperature Materials and Processes. 2005. Vol. 24, Iss. 4. P. 239-258. DOI 10.1515/HTMP.2005.24.4.239.

31. Nunes F.C., Dille J., Delplancke J.-L., De Almeida L.H. Yttrium addition to heat-resistant cast stainless steel. Scripta Mater. 2006. Vol. 54, Iss. 9. P. 1553-1556.

32. Konno T.J., Miura E., Tanaka A., Hanada Sh. A TEM study on the simicoherent precipitates in a $\mathrm{Nb}$ 19\% Mo alloy. Acta Materialia. 2005. Vol. 53. Iss. 6. P. 1783-1789.

33. Billingham J., Bell P.S., Lewis M.H. Vacancy short-range order in substoichiometric transition metal carbides and nitrides with the $\mathrm{NaCl}$ structure. I. Electron diffraction studies of short-range ordered compounds. Acta Crystallographica. Section A. 1972. Vol. A28. № 6. P. 602-606. DOI 10.1107/S0567739472001524.

34. Landesman J.P., Christensen A.N., De Novion C.H., Lorenzelli N., Convert P. Order-disorder transition and structure of the ordered vacancy compound Nb6C5: powder neutron diffraction studies. Journal of Physics C: Solid State Physics. 1985. Vol. 18. № 4. P. 809-824.

35. Kesri R., Hamar-Thibault S. Structures ordonnees a longue distance dans les carbures mc dans les fonts. Acta Metallurgica. 1988. Vol. 36. Iss. 1. P. 149-166.

36. Gusev A.I., Rempel A.A. Order-disorder phase transition channel in niobium carbide. Physica Status Solidi (a). 1986. Vol. 93. Is. 1. P. 71-80.

37. Steel Castings Handbook. Supplement 9. High Alloy Data Sheets. Heat Series / Ohio: Steel Founder's Society of America, 2004. 60 p.

38. Ibanez R.A.P., De Almeida Soares G.D., De Almeida L.H., Le May I. Effects of Si content on the microstructure of modified-HP austenitic steels. Mater. Charact. 1993. Vol. 30. P. 243-249.

39. Caballero F.G., Imizcoz P., Lopez V., Alvarez L.F., Garcia de Andres C. Use of titanium and zirconium in centrifugally cast heat resistant steel. Materials Science and Technology. 2007. Vol. 23, Iss. 5. P. 528-534.

40. Brizes Wm.F., Cadoff L.H., Tobin J.M. Carbon diffusion in the carbides of niobium. Journal of Nuclear Materials. 1966. Vol. 20. Is. 1. P. 57-67.

41. Talis A., Kraposhin V. Finite noncrystallographic groups, 11-vertex triangulated clusters, and polymorphic transformations in metals. Acta Cryst. A. 2014. Vol. 70. P. 616-625.

42. Kondrat'ev S.Yu, Kraposhin V.S., Anastasiadi G.P., Talis A.L. Experimental observation and crystallographic description of M7C3 carbide transformation in $\mathrm{Fe}-\mathrm{Cr}-$ Ni-C HP type alloy. Acta Materialia. 2015. Vol. 100. P. 275-281.

43. Kraposhin V.S., Talis A.L., Demina Ye.D., Zaytsev A.I. Kristallogeometricheskiy mekhanizm srastaniya shpineli i sulfida margantsa v kompleksnoye nemetallicheskoye vklyucheniye. Metallovedeniye i termicheskaya obrabotka metallov. 2015. № 7 (721). S. 4-12. (rus.) 


\section{СВЕДЕНИЯ ОБ АВТОРАХ/AUTHORS}

КОНДРАТЬЕВ Сергей Юрьевич - доктор технических наук профессор Санкт-Петербургского политехнического университета Петра Великого.

195251, Россия, г. Санкт-Петербург, Политехническая ул., 29.

E-mail: petroprom2013@yandex.ru

KONDRATYEV Sergei Yu. - Peter the Great St. Petersburg Polytechnic University.

29 Politechnicheskaya St., St. Petersburg, 195251, Russia.

E-mail: petroprom2013@yandex.ru

СВЯТЫШЕВА Екатерина Вадимовна - инженер Центрального научно-исследовательского института конструкционных материалов «Прометей».

191015, Россия, Санкт-Петербург, Шпалерная ул., 49.

E-mail: svyatyscheva.ek@yandex.ru

SVIATYSHEVA Ekaterina V. - Central Research Institute of Structural Materials "Prometey”.

49, Shpalernaya str., St. Petersburg. Russia, 191015.

E-mail: svyatyscheva.ek@yandex.ru

АНАСТАСИАДИ Григорий Панеодович - доктор технических наук профессор Санкт-Петербургского политехнического университета Петра Великого.

195251, Россия, г. Санкт-Петербург, Политехническая ул., 29.

E-mail: anastas45@yandex.ru

ANASTASIADI Grigorii P. - Peter the Great St. Petersburg Polytechnic University.

29 Politechnicheskaya St., St. Petersburg, 195251, Russia.

E-mail: anastas45@yandex.ru

ДАНИЛОВА Марина Андреевна - инженер-исследователь Санкт-Петербургского политехнического университета Петра Великого.

195251, Россия, г. Санкт-Петербург, Политехническая ул., 29.

E-mail: m.danilova@mail.ru

DANILOVA Marina A. - Peter the Great St. Petersburg Polytechnic University.

29 Politechnicheskaya St., St. Petersburg, 195251, Russia.

E-mail: m.danilova@mail.ru 